\title{
Modelling of integrated multi-energy systems: drivers, requirements, and opportunities
}

\author{
P. Mancarella ${ }^{1}$, G. Andersson ${ }^{2}$, J.A. Peças-Lopes ${ }^{3}$ and K.R.W. Bell ${ }^{4}$ \\ ${ }^{1}$ The University of Manchester, Manchester, UK \\ ${ }^{2}$ ETH Zurich, Zurich, Switzerland \\ ${ }^{3}$ INESC TEC \& FEUP, Porto, Portugal \\ ${ }^{4}$ University of Strathclyde, Glasgow, UK \\ p.mancarella@manchester.ac.uk, andersson@eeh.ee.ethz.ch,jpl@fe.up.pt, keith.bell@strath.ac.uk
}

\begin{abstract}
There is growing recognition that decarbonisation of existing uses of electricity is only 'part of the story' and that closer attention needs to be given to demand for energy in heating or cooling and in transport, and to all the energy vectors and infrastructures that supply the end-use demand. In this respect, concepts such as 'multi-energy systems' (MES) have been put forward and are gaining increasing momentum, with the aim of identifying how multiple energy systems that have been traditionally operated, planned and regulated in independent silos can be integrated to improve their collective technical, economic, and environmental performance. This paper addresses the need for modelling of MES which is capable of assessing interactions between different sectors and the energy vectors they are concerned with, so as to bring out the benefits and potential unforeseen or undesired drawbacks arising from energy systems integration. Drivers for MES modelling and the needs of different users of models are discussed, along with some of the practicalities of such modelling, including the choices to be made in respect of spatial and temporal dimensions, what these models might be used to quantify, and how they may be framed mathematically. Examples of existing MES models and tools and their capabilities, as well as of studies in which such models have been used in the authors' own research, are provided to illustrate the general concepts discussed. Finally, challenges, opportunities and recommendations are summarised for the engagement of modellers in developing a new range of analytical capabilities that are needed to deal with the complexity of MES.
\end{abstract}

Index Terms - multi-energy systems, integrated energy systems, whole-energy systems, energy systems modelling, energy systems integration, energy systems modelling tools.

\section{INTRODUCTION}

Concerns about anthropogenic climate change driven by burning of fossil fuels have moved policy makers', the energy industry's and energy users' attention away from simply the technologies, commercial frameworks and institutions that promise to deliver a sufficiently reliable supply of energy at least cost towards what was described in 2008 by Sautter et al. as the "energy trilemma" [1] involving interactions between cost, reliability and the environment. A number of commentators now extend this to a 'quadrilemma' [2] in which societal choices are to be made between affordability of energy, security of supply, sustainability (not only in respect of carbon emissions but also around use of natural resources such as water) and social acceptability, e.g., in respect of visual impacts, safety concerns, comfort, perceptions of health impacts, effects for the wider economy and so on.

An acceptable resolution of the different dimensions of the quadrilemma presents an increasing challenge. Many of the earliest discussions about decarbonisation focused on the potential benefits of energy efficiency (many of which have, to date, not been fully realised) and the scope for decarbonising production of electrical energy. However, there is now a growing recognition that decarbonisation of existing uses of electricity is only part of the story and that closer attention needs to be given to how demand for energy in heating or cooling and in transport can be met in such a way as to satisfy the quadrilemma. In this way, decarbonisation of the whole energy system, and not only electricity, can be successfully and most effectively achieved. This has recently brought the attention of policy makers and researchers alike to the need for taking a holistic whole-energy system perspective on the relevant activities. In this respect, concepts such MultiEnergy Systems (MES) [3] have been put forward and are gaining increasing momentum, with the aim of identifying how energy systems that have been traditionally operated, planned and regulated in independent silos can be brought together ('integrated') so as to improve their collective technical, economic, and environmental performance.

In fact, there are many choices both in how energy is used and in how it is converted into a usable form, considering that the purpose of any final energy use is eventually to provide a service, being it a certain temperature in buildings, lighting, power for computers, etc. In the context of energy systems integration the question therefore arises as to what is the optimal combination of natural resources, technologies and infrastructure to provide the final end-use services with no pre-concept on any specific energy vector. Indeed, the 
challenge for energy users is to know which options are most likely to meet their needs in terms of cost, reliability and comfort; for energy producers to know what the demand will be for different forms; for engineers responsible for the planning and operation of shared infrastructure to know the size and location of both demand and the available resources for conversion; and for policy makers with their eyes on the quadrilemma to know what commercial frameworks and institutions seem best suited to enabling the different actors to make rational decisions that, collectively, meet policy objectives. Unfortunately, these choices are made especially difficult by many uncertainties, among which are:

- The extent of economic development and how it affects demand for energy;

- Societal changes that affect how energy is used;

- The use of resources and access to future reserves that affect their costs;

- Technology developments affecting the performance characteristics and costs of end use, conversion and transfer of energy;

- Political developments that influence policy priorities and preferences for particular types of intervention (or no intervention) in the form of laws and institutions.

Some of these uncertainties can be addressed, with limited fear of the magnitude of adverse impacts in the short-term, in small-scale (but large enough to be statistically significant) trials or experiments where innovations are tested and the outcomes measured and assessed and used to inform policies or investment decisions. However, many are impossible to test either because the learning would take too long or because the risks of unintended consequences are too high. If actors' choices are to be in any way informed, the impacts of innovations must therefore be evaluated through modelling.

Power system engineers are familiar with the need for modelling. Power systems are large, complex, dynamic systems for which intuition alone cannot provide confident predictions of responses to disturbances. Moreover, the consequences of getting something wrong - in a worst case, an entire power system suffering a blackout - preclude a trial and error approach to dealing with uncertainty. Fortunately, power system engineers have spent many years developing and testing models of individual items of equipment, of equipment integrated within systems and, in recent decades, of economic actors interacting with the system through markets. This has normally been done by developing procedures for the determination of model parameters and conventions for defining sets of equations and the values of input variables in order to estimate, with confidence, a system's state under a given set of conditions. Moreover, many widely used software tools have been developed and tested over a number of years and reliably solve particular sets of equations and can be used to assess what would be the result of some particular future set of circumstances. However, this wealth of capability extends, in respect of electricity, only to electrical energy systems with, to a very large extent, the final use of electrical energy treated exogenously ${ }^{1}$. In contrast, what is becoming increasingly clear

\footnotetext{
${ }^{1}$ This also happens with comparable capabilities in other sectors, e.g., gas and heat, not only in electricity.
}

is that, given the choices and interactions between different energy sectors and vectors in a truly MES context, this is inadequate. Starting from the uses to which energy - in some form - is put, i.e., the aforementioned 'energy services', and having in mind the quadrilemma, what is required is therefore some approach that allows the whole energy system to be modelled. This would enable, for example, transport that uses internal combustion engines supplied from a system of oil extraction, refinement, distribution and storage to be compared with Electric Vehicles (EVs) and their impact on the power system, or Electric Heat Pumps (EHPs) and their impact on demand for electricity to be compared with fossil fuels or biomass for heating. In this way, optimal solutions for energy systems integration can also emerge, as energy sectors and vectors are by definition no longer treated independently. A conceptual picture of integration of a modern power system with other energy systems, sectors and markets (including externality markets, such as for emissions) is provided in Fig.1.

This paper addresses the need for modelling of MES which is capable of assessing interactions between different sectors and the energy vectors they are concerned with so as to bring out the benefits and potential unforeseen or undesired constraints and drawbacks arising from energy systems integration. The needs for such new modelling and studies are also to be put in the context of new scenarios and challenges for future power systems and power systems engineers, including: economic operation with large scale penetration of renewable plant characterised by very low marginal cost and high investment required for relatively low capacity factor and capacity credit variable generation; increasing requirements for flexibility; new 'Smart Grid' technologies emerging in the market (from batteries and EVs to smart appliances and pervasive ICT infrastructure); concerns on power system resilience to extreme events possibly driven by climate

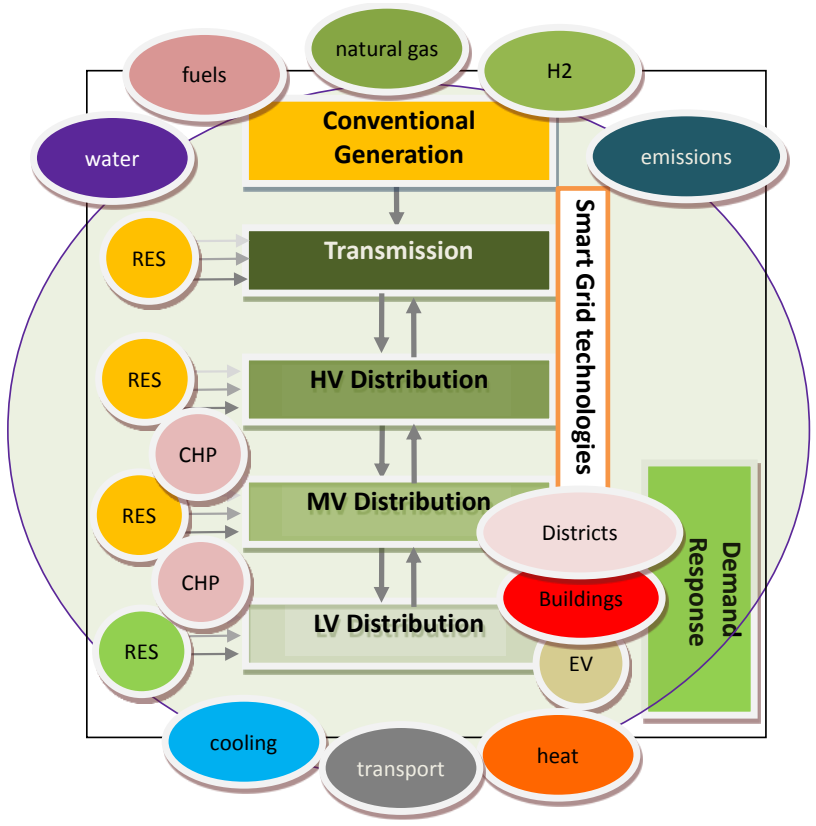

Figure 1. A representation of the relationship between a power system and other energy systems. 
change; and the limitations of maintaining a deterministic levelised cost approach for system planning in the presence of multiple uncertainties (including policy support for low carbon technologies, uncertainty in fuel prices, etc.). As will be argued in this paper, MES integration provides a useful approach to deal with these power system challenges.

The next section goes more deeply into the drivers for MES modelling (the 'why' question) and the needs of different users of models (the 'who' question). Then, there is a discussion of what models might be used to quantify and how they are framed mathematically, also considering some of the challenges and practicalities of such modelling, not least the choices to be made in respect of spatial and temporal dimensions, amongst others (the 'what' and 'how' questions). The subsequent two sections of the paper present some examples, firstly glancing through existing MES tools and their capabilities and, secondly, of studies from the authors' own research demonstrating specific MES models and some applications. Finally, before concluding, we provide a section about gaps and opportunities, with the aim of opening up new avenues of research in this area for the engagement of modellers in developing a new range of analytical capabilities.

\section{MES MODELLING: WHY AND WHO}

\section{A. Drivers for and examples of MES}

As mentioned earlier, the need for decarbonisation of the whole energy system is one of the key drivers for energy systems integration. In fact, while electrical energy already plays a key role today, this role is likely to become even more important in the future considering potential electrification of other sectors, such as heating and transport [4]. However, when looking at the whole MES problem, a number of options can be identified in terms of energy systems integration [5] rather than electrification, especially in the light of greenhouse gas emission reduction. For example, it is well recognised that use of natural gas in boilers for heat production is characterised by low thermodynamic efficiency [6], while the use of distributed multi-generation plants [7], [8] for cogeneration of electricity and heat (Combined Heat and Power - CHP) as well as potentially cooling in trigeneration (Combined Cooling Heat and Power - CCHP) [9] can bring energy saving [10], emission reduction [11], [12] and economic benefits [13] relative to separate production of the same energy vectors.

The role of integration of energy vectors and high efficiency generation in CHP and CCHP is also likely to increase in importance with the rising number and sizes of urban areas. By 2040, it is estimated that $63 \%$ of the world population will be living in cities [14], with high density of energy consumption in different forms. (Think, for instance, of 'vertical' urban areas with more and more high rise buildings). High density energy demand is an important factor in the installation of cost efficient, high capital expenditure (capex) infrastructure such as heat networks (besides the electricity ones), in case competing with gas networks [15]. Having the option of more networks in turn enables multiple and flexible supply of energy in district and community energy systems [16].
However, the planning and operation of multi-generation, distributed multi-energy systems and community energy schemes needs to be coordinated with the rest of the electricity-heat-fuel system to make optimal use of the available resources, which again motivates the rationale for energy systems integration. For example, it may be inefficient to use CHP plants in heat-led mode if surplus renewable energy is available which could be used in heat pumps or electric boilers to supply heat. The integrated operation of $\mathrm{CHP}$ and electric heating systems has therefore been proposed [17]-[20] to maximise cost-effective renewable energy integration. In addition, this also potentially brings significant economic benefits to the plant owners [21]. Further, the pair CHP-EHP [22] can be demonstrated to be able to improve significantly fuel conversion efficiency and plant flexibility by operating as an 'equivalent cogeneration plant' with flexible cogeneration ratio [23].

In some instances, a broader consideration of multiple energy vectors can afford new opportunities. For example, it is possible to use thermal energy storage [24] and multi-source arbitrage opportunity [25] in district energy systems to provide demand response and various services [26], [27] to the power system, as well as for active network management purposes [28]. Similarly, through the so-called power-to-gas process that uses renewable electricity to generate hydrogen or synthetic natural gas [29]-[31], the gas system could be used in the future to, for example, create network arbitrage opportunities and bypass electrical/gas network constraints [32] or as a seasonal storage resource [33]. Similarly, there are a number of examples where integrated operation [34]-[38] and expansion [39], [40] of electricity and gas networks could bring significant benefits.

Besides economic and environmental benefits, issues such as system reliability and resilience [41] must be addressed too. In fact, particular configurations of distributed multi-energy systems that could be operated as microgrids are promising in terms of enhanced reliability [42] and resilience [43]. On the other hand, MES modelling, for example in the case of integrated electricity and gas network operation, can also highlight inter-network reliability [44], [45] and flexibility [46] issues that could not be identified via independent system modelling.

\section{B. Need for, users and scopes of MES models}

\section{1) Why MES modelling?}

According to the statistician George Box: "Essentially, all models are wrong, but some are useful" [47]. The next sections thus discuss some of the choices to be made in making it possible to build, use and maintain models that, depending on their particular purpose, are not too wrong. However, the first question to ask is: who are the main users of MES models?

The engineering perspective is concerned with meeting system users' requirements at least cost and so doing safely and with sufficient reliability ${ }^{2}$. A particular challenge is presented by the often fragmented nature of ownership and

\footnotetext{
${ }^{2}$ See Section III.B for a discussion on criteria and metrics that can inform engineering decisions.
} 
operational responsibilities in energy systems in many parts of the world to date, e.g., where regional and national gas and electricity systems are managed almost totally independently of each other. This is despite their physical interaction, most obviously in respect of gas supplies required by combined cycle gas turbine power plants for the production of electricity and by CHP plant that operates primarily for the production of heat with electrical energy as a valuable bonus. On the other hand, where heat networks and district energy systems exist, they are typically not geographically extensive, being limited to a few tens of $\mathrm{km}$ at most around urban centres (mostly due to the economics of a high investment and 'lossy' heat transport infrastructure that requires suitable energy density [48]) and developed and operated by local utilities, often municipalities ${ }^{3}$. Cooling systems tend to be highly localised as well for similar reasons. Finally, the other main 'user' of energy, namely, the transport sector, has some aspects that are quite coordinated, e.g., the rail network, but the largest one, for road vehicles, is highly decentralised albeit with some common infrastructure related to extraction, refinement and distribution of fuels.

The fragmentation of the energy system has been made more extreme by liberalisation policies that favour splitting up of responsibilities among a number of parties, that ideally compete with each other with the minimum left to regulated activities concerning aspects in which competition is judged to be impossible or problematic. Given that energy network infrastructures are often regarded as natural monopolies, the interaction between regulated and non-regulated actors in MES exacerbates even further the fragmentation issue.

Separation of responsibility for operation of existing facilities is arguably not a problem, especially if liberalisation has brought with it a coherent set of codes governing the essential interactions between the different parties. An example is that of electricity Grid Codes that determine the capability of independently owned generators to provide ancillary services to a system operator (even if it might be left to a market to determine which of a set of available capabilities is actually used). With only moderate change in the externalities affecting the energy subsystems, this can also work satisfactorily in respect of investment in new facilities. However, with such radical change in the supply of energy being required in the next few decades, it is no longer sensible to neglect interactions between the energy subsystems and of options that may have moderate benefits in any of them if considered alone but which can be very attractive for the energy system as a whole. On the other hand, the incentives seen by industry to invest in such solutions might not be strong enough and are compounded by a general trend away from medium capex, medium operational expenditure (opex) solutions (such as, in electricity production, fossil fuelled power stations) to high capex, low opex solutions (such as renewables or nuclear power, possibly supported by extensive network and supply redundancy or backup). The challenges for optimal investment in a MES context are further exacerbated by misalignment in regulation of or incentives to

\footnotetext{
${ }^{3}$ Exceptions to this include regions with easily accessible geothermal resources, such as Iceland, which have developed to maximise the utilisation of such resources.
}

different networked assets. For instance, heat networks are, in many places, effectively treated as private investments while electricity and gas networks (that may be seen sometimes as 'competing' besides 'complementary' assets) are heavily regulated and often enjoy some forms of 'social support'; this can, for instance, happen in the form of privileged conditions of financing. If 'business as usual' regulatory and commercial frameworks will not drive the whole energy system towards a resolution of the quadrilemma, there is a need for them to be changed, i.e., a need for a revision of the set of responsibilities or opportunities that different institutional actors - owners, operators, market operators, system operators, energy retailers, etc. - have, the development of new financial arrangements, or the introduction of new regulations, or obligations on existing parties. However, these changes can typically only be made by legislators who will - or should - want evidence that they will have the desired effect which, in turn, points again to the need for modelling.

\section{2) Use cases and users of MES models}

The exact responses to a set of signals from different market actors with different perspectives and priorities is very difficult to model; hence, moves towards changes in government level energy policy and any associated legislation often start from modelled minimisations of whole system long-run costs of meeting a given set of energy service demands, perhaps with some particular constraints such as on total carbon emissions. This is the approach used in various well-known MARKAL or TIMES based models ${ }^{4}$ [49], [50] and might be viewed as setting a target technology mix that policy interventions can be designed to achieve. (See also Section III.F for the high level mathematical approach). If the set of model variables and constraints allows it, a second run of the modelling can attempt to model these interventions, directly where possible but otherwise through expedient adjustment of model inputs. However, given the limitations of current MES models (discussed further in Section IV and Section VI), it would actually be unwise to read too much into the results of the first run. The second run, in which policy interventions are modelled, represents a more valid use. This could be characterised as allowing the running of complex thought experiments or tests of intuition: the policy maker might expect a certain outcome from a certain policy intervention, but the system in which it is to be applied is highly complex. Does the modelling of that system give confidence that the outcome will be as expected? ${ }^{5}$.

It should also be highlighted that the policy perspective on MES modelling and relevant drivers is not only relevant at the country or continent level ${ }^{6}$, but also at local authority or city levels, for instance in planning with respect to future environmental targets and impacts on jobs, potentially in response to higher level targets set out by the Government. (See also Section III for further elaboration on 'scale' aspects.)

\footnotetext{
${ }^{4}$ See Section IV for further discussion on these.

${ }^{5}$ For discussion of this and other philosophical issues around the design and use of models, especially when modelling social systems such as economies for which there has been limited validation of mathematical descriptions of subsystems or their interactions, see, for example, [51].

6 See for example the European Commission's 'Integrated Roadmap': https://setis.ec.europa.eu/set-plan-process/integrated-roadmap-and-actionplan.
} 
Newer modelling of MES can also be highly relevant to energy business actors that aim at developing new business cases, for instance multi-energy providers retailers that try to optimise and risk-hedge their asset portfolio in the light of regulatory requirements [52], energy service companies that assess different integrated energy supply options [26], local developers that are interested in optimising the economics of shared electricity-heat distribution networks [53], and so forth.

Some risks and opportunities that may be the concern of transmission and distribution system operators can benefit from MES perspectives too. An example is that of gaselectricity network interaction, whereby an inability to supply fuel to gas turbines used for system balancing might cause the need to redispatch electrical reserves, with potentially serious consequences that might end up in a cascaded gas-to-electrical system blackout [46]. Similarly, with more and more expectations for distribution network operators to become Distribution 'System' Operators (DSO) and provide local balancing on their distribution network while interacting with the upstream transmission system [54], DSOs could become interested in the potential of actively managing their networks by exploiting the flexibility available in other sectors such as heat [28].

A synthetic representation of potential uses of MES models, especially to address whole-system planning (see also Section III.F), is provided in Fig. 2.

\section{MES MODELLING: WHAT AND How}

\section{A. General aspects of MES modelling: the issue of scales and dimensions}

Generally speaking, as in the analysis of individual sectors, different mathematical formulations could be adopted for simulation and optimization of MES, depending on the purposes and context of the study. In particular, relevant problems might refer to operational or planning aspects. Different perspectives can also be analysed, which usually generates a multi-criteria problem. (See Section III.B).

What is specifically more challenging in MES studies, however, is that different scales, resolutions and representation approaches might need to be followed for different energy vectors and the system as a whole. Such variation may be necessary to deal explicitly with various dimensions of the analysis, particularly in terms of temporal (by providing different time resolutions for the analysis of different energy vectors) and spatial scales, with the latter also entailing the issue of specific network modelling and detail of network representation for different energy vectors.

In the context of evolving power systems the challenges brought about by (variable) Renewable Energy Sources (RES), the emergence of various low carbon technologies (from EVs to EHPs), and the rise of smarter grids as a controlbased operational and planning paradigm as opposed to more

\footnotetext{
7 'Scale' may have different meanings and depending on the source. Here we generally mean the size of the model boundaries, which may also impact on different dimensions of the model resolution e.g., national analysis with low geographical resolution and no network representation; district level analysis with high spatial and network resolution; lifecycle planning with low (e.g., annual) temporal resolution; etc.
}

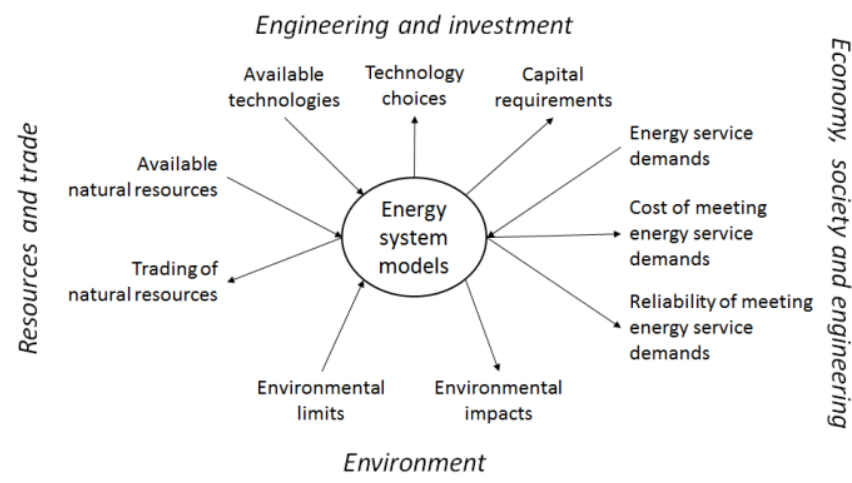

Figure 2. An example of use of MES modelling (adapted from [55]).

classical asset-heavy system planning, mean that specific attention and focus need to be given to specific system operational and network constraints in the analysis. These requirements and challenges are even further exacerbated in MES due to the multiple sectors involved. That is, an MES modeller intending to identify what meets a given set of criteria in respect of the most appropriate set of physical facilities for energy conversion and transfer of energy should ensure that the identified set can actually be operated successfully (and possibly optimally) to meet energy service needs within physical equipment limits. However, a planning study already considers such a large set of variables that to model system operation is highly challenging. Hence, even if the purpose of planning is to enable future operation, in planning models this is often represented through proxies and different time resolutions (including with respect to modelling of uncertainty [56]).

The above almost inevitably leads to judgements on the temporal as well as spatial scales of a model that go beyond classical MES tools such as MARKAL/TIMES used so far in planning, particularly for whole-system studies that are based on bottom-up optimization models that require extreme simplifications such as country level aggregate and annual/seasonal average demand/supply balance. (See also Section IV for further details on this). As discussed in [57], such approximations were accepted and the error involved relatively well understood in a system basically characterised by baseload and fully dispatchable generators (as well as unresponsive demand and little or no energy storage); however, these tools in their current form may be unsuitable to capture the complexity of current and future systems where high-resolution aspects across scales (e.g., spatial details such as network-constrained location of resources, and operational details such as temporal variability of RES and usage of storage) may be important in planning.

A schematic representation of the temporal and spatial scale considerations, alongside some planning and operational aspects of MES and some existing tools, is depicted in Fig. 3 (adapted from [58]).

A further dimension of the problem that is becoming more and more evident is, as again pointed out in [57], that the tools we usually develop tend to focus on 'engineering' or 'economic' understanding and issues, while technologies and their deployment often depend on (global to regional and local 
scale) political decisions, human behaviour and resistance to change, public acceptance of new technologies, and so forth. Bringing these more 'social' aspects into our modelling is highly desirable as well as dauntingly challenging, but should in any case be considered somehow, perhaps in terms of uncertainty modelling, stress tests, and so on.

A relevant synthesis of modelling challenging considering scales, resolutions and dimensions and associated uncertainty is provided in Fig. 4 (adapted from [57]).

\section{B. MES multi-criteria mathematical formulations}

As mentioned earlier, in general terms developing a model for operational or planning or other purposes (e.g., scenario exploration) may have to do with multi-criteria analysis, which is explored here in the context of MES.

\section{1) Multi-criteria decision making}

A multi-criteria problem usually requires the adoption of the following steps (elaborated from [59]):

a) Problem identification and global description;

b) Defining the scope and objectives for the problem;

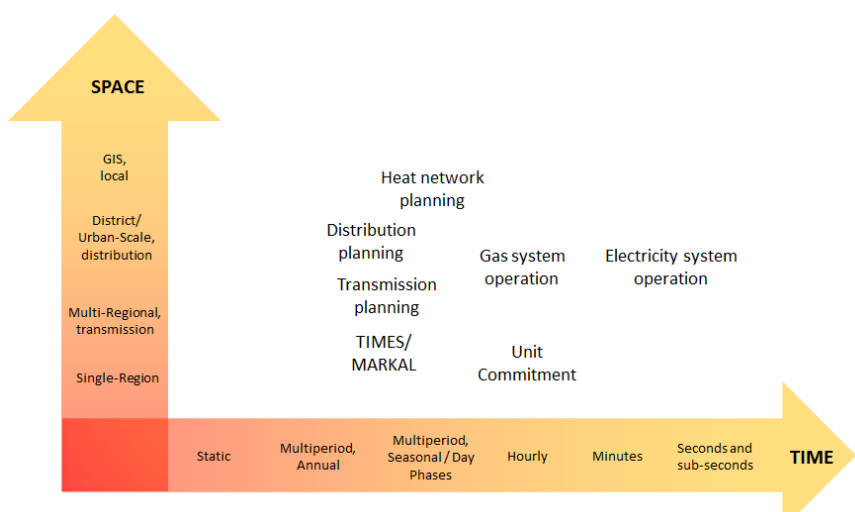

Figure 3. Spatial and temporal scales and MES operational and planning aspects Scale (adapted from [58]).

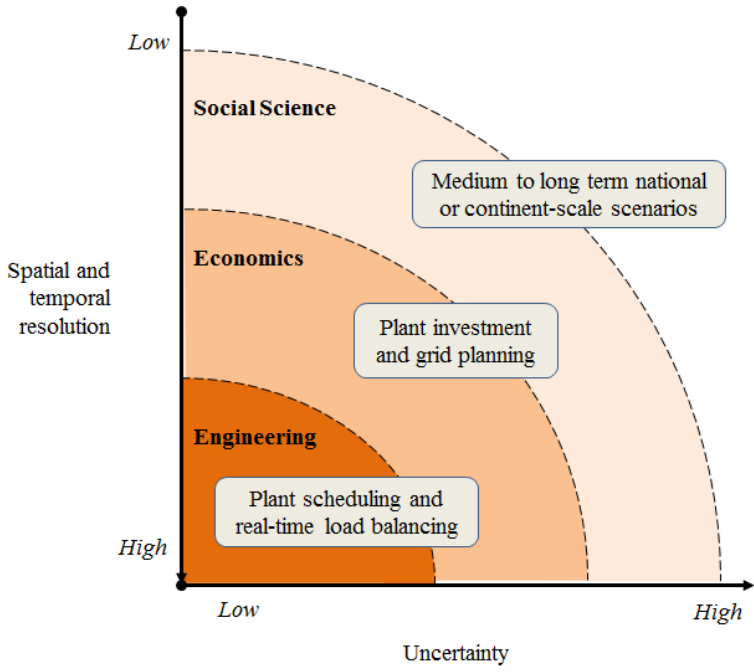

Figure 4. Scales, resolutions, dimensions and uncertainties in MES modelling (adapted from [57]). c) Problem formulation, including the identification of decision variables, alternatives, criteria and attributes;

d) Mathematical modelling, with the relevant specific formulation of objective function and constraints.

Taking as a reference a generic MES planning problem (operational problems could be dealt with in a similar way), the process starts when the decision maker considers the design of a strategic and long-run study ${ }^{8}$ for a given system, taking into account different criteria. The decision maker is assumed to be an authority of the system under analysis, with power and legitimacy to decide among a set of feasible options. The MES plan should be holistic, by gathering strategies applied in both the demand and supply sides of the power system, heating/cooling system, fuel systems, as well as in the transport sector, and capturing the relevant forms of interactions.

Although there is no formal guideline for identifying an adequate decision situation, this can be typified by the following elements:

- A set of decision variables and alternatives;

- A set of criteria;

- A set of attributes.

The alternatives are options, plans or strategies that represent possible solutions for the problem. These alternatives can be defined by considering the investments and policies that are being studied by the decision maker. Hence, the alternatives' identification reproduces a set of potential hypotheses for a given MES. Each alternative is a strategy, enclosing a set of decision variables, e.g.:

- Changes in demand (increase/decrease) in a MES associated with the adoption of different energy solutions;

- Installed capacity of RES and in general MES technologies, e.g., business-as-usual or MES/RES increase;

- Use of storage systems for different energy vectors (centralised or decentralised);

- Sustainable mobility options: e.g., efficient internal combustion vehicles, use of biofuels, behavioural change, or strategies based in EVs introduction.

\section{2) Criteria and attributes}

As in all energy systems modelling problems, different criteria can be considered to effectively support decision making in different MES (operational and planning) problems.

The specific criteria selection is one of the first steps within the decision making process. In order to verify the suitability of the chosen criteria within the specific context of the work, one should confirm that:

8 Concerning the time horizon, without loss of generality the methodology may be assumed to be carried out for long-run energy planning, from a few years to decades (also answering the "when" question). 
- What is apprehended by each criterion is sufficiently intelligible for each of the stakeholders;

- $\quad$ Each criterion is perceived to be a relevant instrument for comparing potential actions along the scale associated with it, without prejudging their relative importance, which could vary significantly among the stakeholders.

In addition, a coherent family of criteria must be:

- Exhaustive: all important points of view must be included;

- Consistent: if two alternatives $\mathrm{A}$ and $\mathrm{B}$ are equivalent except in criterion $k$, and $A_{k}$ is better than $B_{k}$, then $\mathrm{A}$ must be at least as good as B;

- Non-redundant: eliminating a criterion leads to the violation of one of the preceding axioms.

Furthermore, there are other desirable properties, as follows:

- Intelligibility: the number of criteria must be relatively low;

- Operationality: the family of criteria must be accepted by the stakeholders and decision-makers.

When it comes to the criteria assessment, an attribute is associated to each criterion, which serves as yardstick. Attributes are generally characteristics, qualities or performance parameters of alternatives. That is to say, an attribute is a measurable quantity expressed via a metric or indicator whose value reflects the degree of achievement for a given criterion, to which the attribute is ascribed.

The association of an attribute to a criterion requires the fulfilment of the next properties:

- Measurability: an attribute is measurable if it is reasonably practical to assign a value in some scale to the attribute for a given alternative;

- Comprehensiveness: an attribute is comprehensive if its value is sufficiently indicative of the degree to which the criterion/objective is met.

To exemplify, a generic criterion $C_{i}$ could gather a set of attributes $X_{i}$ (and relevant sub-attributes), as in the following:

- $C_{l}$ : Environmental impact

○ $\quad X_{1}: \mathrm{CO}_{2}$ emissions from transport sector;

- $C_{2}$ : Economic assessment

○ $X_{2}$ : Overall alternative costs comprising, for example: $X_{3}$ : Costs of Storage Facilities; $X_{4}$ : Costs of Electric Mobility;

- $\quad C_{3}$ : Adequacy/Reliability of the generation system (and in case other resources) in terms of reliability

\section{○ $\quad X_{3}$ : Loss of Load Expectation index}

In a MES context, criteria that are typically used (and relevant attributes/metrics) may refer for instance to:
- Economics, making for example use of attributes and relevant metrics such as annual costs/revenues/profits, net present values, pay back times, etc. [60], [61];

- Energy consumption/saving, by type of vector or altogether, and assessing the likes of primary energy use and saving relative to a reference case [10], [60];

- Emissions/emission savings, for example considering global emissions and emission savings of $\mathrm{GHG} / \mathrm{CO}_{2}$ or local emissions/pollution, such as for $\mathrm{CO}, \mathrm{NOx}$, etc. [62];

- Integration of RES and low carbon technologies, adopting for example metrics such as volumes of RES integrated into a given system, renewable energy curtailment, distribution network's hosting capacity, etc.;

- $\quad$ Security of supply, reliability and resilience, using metrics such as expected energy not supply, frequency and duration of interruptions, etc.;

- Comfort level, for instance making using of indicators such as average indoor temperature [63], expected energy to be curtailed by building management systems, etc.

\section{The temporal scale}

\section{1) Dynamics and time resolutions}

Power system engineers are familiar with judgements on the temporal dimension. Many power system phenomena are dynamic, meaning that, if system responses to disturbances are to be represented correctly, differential equations need to be solved. The time constants of variations on an actual power system range between $\mu$ s and, in the case of automated equipment such as on load tap changers or manual actions taken by operators, minutes, and, for scheduling of generation, hours. Practical modelling generally indicates that assumptions are made that, for example, fast phenomena have reached equilibrium. What is regarded as 'fast' in this sense depends on the question being asked and whether the modeller judges it likely that those phenomena, under the external conditions being modelled, would have led the system into an unacceptable operating region.

Judgements similar to those above are equally present in modelling of MES but typically cover a wider range of timescales going out to hours in, for example, the case of transfer of gas through a gas transmission network or energy user behaviour, or months in the case of seasonal influences on the need for energy for heating or cooling and seasonal storage [64]. Such issues often lead to separation of variations that arise in different timescales into different models. In one model, a particular set of variables, e.g., electricity demand in a power system model, is taken as a fixed, exogenous set of assumed values; on the other hand, another model, e.g., of air temperature variations within a building and the loading on a heat pump, might treat the power system's ability to supply the required power as being infinite. Or for instance different time scales could be used for different networks, such as electricity and heat [65]. The modelling of storage - the transfer of a unit of energy from one period of time to another 
and the cost and value of doing that - is particularly sensitive to choice of timescales. Interesting discussions on the need for high resolution modelling can for instance be found in [66]. As a relevant case (as the 'building brick' of multi-energy demand), high-resolution model for multi-energy residential load profiles can be found in [67].

2) Soft-linking and representation of operations in planning

One emerging option for modellers, in order for demand in a power system model to correctly reflect weather variations and interventions regarding, for example, building insulation, and in order to be secure that the consumption of power does not overload the distribution network and can actually be sourced from available generation, is to 'soft-link' different models to ensure that their respective results are coherent (see, for example, [68]). In this, the key is often to correctly define how more detailed representations of a particular variable in one model constrain values of that variable in another model in which it has a much simpler representation. For instance, to use again a power systems example, the results of a detailed quantification of generation adequacy in one model might be captured in another by requiring a certain minimum total generation capacity.

Of relevance to this discussion is also the question as to what level of operational detail is needed in energy system planning [69]. For example, work in recent years has discussed how it is possible to reduce the order of operational complexity of unit commitment problems by suitable generation clustering [70], while it has also been shown how fully linear models could be used for power system simulation while capturing a number of details with minimum loss of accuracy [71]. Such modelling is expected to become more and more important for applications in planning, and especially with extension to the multi-energy domain, as also widely discussed in Section IV.

\section{The spatial scale}

As already mentioned, other modelling choices, at both the operational and planning stages, concern spatial scale. Arguably, the main reasons for modelling different locations are $(a)$ that energy service needs and the availability and cost of different energy resources depend on location; and $(b)$ the transfer of energy from one location to another depends on the transfer infrastructure - wires, pipes, tankers, etc. - that has a cost and is increasingly difficult to expand due to public objections. A finer scale representation promises greater accuracy, but also increases the burden on collection and management of data and increases the size (as well as complexity, given the nonlinearity of most network equations - see also below) of the model.

\section{1) From homes to countries}

Looking at the available literature and proceeding from a spatial bottom up perspective, one of the basic 'bricks' of energy utilization is the home, which is also the simplest form of MES, considering that multiple energy types are required to supply the basic needs of lighting, thermal comfort, etc., and that multiple energy vectors can be used for different appliances. Besides [67], which develops an explicit stochastic high-resolution model for multi-energy residential consumption, several papers have been published that (in some cases only implicitly) deal with building-level MES and optimise their use, for example in the context of optimal planning of multi-energy devices in buildings [72], home energy management systems ([73], also including comfort level considerations), control of 'electrified' buildings facilitated by smart meters [74], and distributed energy markets [75].

Stepping outside the building, district energy systems are the next level of spatial aggregation. This is an area of important expansion given the recent interest in smart districts and community based energy systems. Several papers have then dealt with techno-economic and environmental studies of districts or small towns, such as [76], which provides the basis for design of an "eco-town", [77], describing a co-simulation model for multi-energy districts, or [78], which deals with GIS applications for multi-energy network design. Another relevant recent work is [79], which shows the importance of including electrical network constraints (even if in a simplified manner) in MES planning. Microgrids could also be considered a specific application relevant to the district-level scope, and a few papers have recently been published that more or less explicitly address multi-energy microgrids [80][83].

Cities are another 'natural' form of MES, and integrated energy system analysis can go well alongside the concept of smart cities to improve sustainability [84]. The book [85] is an excellent introduction to urban energy systems and their modelling. Of relevant interest may also be new approaches that are being considered to model cities as groups of energy hubs [86] or distributed multi-generation plants [87].

Finally, there are plenty of papers dealing with regional and country and even continent wide applications by using different tools, typically without considering system operation and infrastructure details in the modelling (see for instance [88], [89]).

The papers just reviewed mostly deal with specific spatial scope. However, as mentioned earlier one of the big arising questions in MES modelling is how to integrate and account for different scales and resolutions, in this case specifically for the spatial one. One example with respect to heating scenarios is provided in [58], where the modelling is carried out with 'spatially explicit' considerations, similarly to [90], where it is shown that different spatial resolutions provided different optimal solutions to the heating supply problem.

\section{2) Energy vector and energy conversion representation}

Dealing with the spatial scale in MES inevitably leads to discussion on the relevant energy vectors and modelling of the devices that perform conversions between different forms of energy.

Reference [91] and relevant works from the same project (amongst others, [92], [93]) have established a well-known approach for modelling and optimization of MES, explicitly considering conversion and transportation characteristic of multiple energy vectors. More specifically, the energy hub modelling framework is based on the idea of developing 
input-output relationships ${ }^{9}$ to analyse multi-energy conversion of a specific energy system in a synthetic way, also allowing the modelling of the interactions among hubs through different energy networks. From a system point of view, an energy hub, whose boundaries are flexible, owing to the generality and scalability/modularity of the modelling approach, represents a part or a unit of a generic MES with mixed energy vectors, and is characterised by basic 'features' such as inputs and outputs, conversion, and storage of different energy types $[95]^{10}$. An example is provided in Fig. 5 [96], with a hybrid energy hub with multiple energy vectors and typical conversion elements (as one might find, for example, in a commercial building), namely, power electronic converters for integration of local RES, a micro-turbine, a heat exchanger for district heating network connection, and thermal energy storage.

A basic formulation of the input-output relationship in an energy hub (basically, its multi-energy balance equations) can thus be put as

$$
\mathbf{v}_{o}=\mathbf{H} \cdot \mathbf{v}_{i}
$$

where $\mathbf{H}$ is the hub's overall input/output efficiency matrix connecting the plant inputs $\mathbf{v}_{i}$ (e.g., electricity and gas) to the plant outputs $\mathbf{v}_{o}$ (e.g., electricity, heat, cooling, and transport energy). A more complete representation can also include storage components and dynamics. (See, for example, [97], [98]). Generally, the components of the matrix $\mathbf{H}$ can be determined by visual inspection of the hub topology, while an algorithm to automatically form it in a symbolic calculation context is provided in [99].

In energy hub modelling, as well as in other typical MES modelling used for system analysis, the relevant energy efficiency relationships (including off-design performance models [99]) are thus captured through a black-box approach [7] that gives only a synthetic representation of the conversion devices. This approach is very useful to reduce the level of complexity and the set of parameters and variables to describe a MES, while maintaining an adequate level of accuracy. In principle, different sub-systems may be treated with different levels of simplifications/reductions (similarly to what discussed above for the temporal resolution), which is an important task left to the modeller.

\section{3) Energy network representation}

Besides the conversion characteristics of multi-energy devices and systems, in MES modelling it is crucial to develop a representation of the different types of networks involved in the analysis, e.g., for electricity, heat/cooling (at different temperatures/pressures and even physical forms, such as hot water or steam), gas, hydrogen, etc. In particular, in network modelling the physics of each network needs to be specifically

\footnotetext{
${ }^{9}$ See also the milestone work on input-output models in economics by Leontief [94].

${ }^{10}$ It is of interest to stress that an 'energy hub' is a mathematical representation of a physical system rather than the physical system itself, exactly because any MES could be modelled as a hub, allowing, in particular, the generalization of classical power system optimization techniques (e.g., economic dispatch and optimal power flow) to the multi-vector case [91]).
}

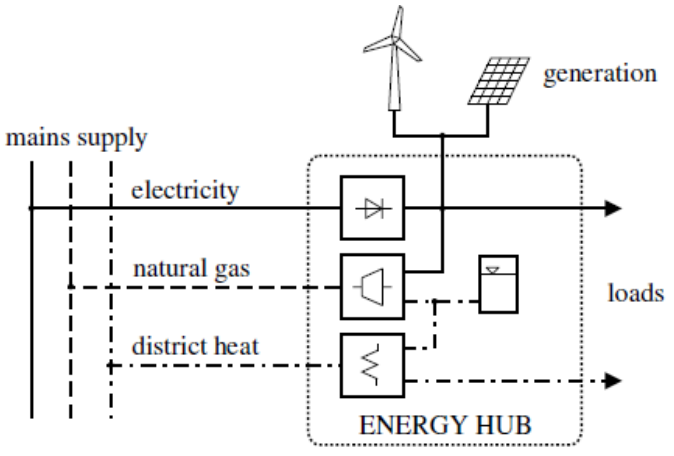

Figure 5. Example of hybrid energy hub (taken from [96]).

considered case by case, and when analyzing multiple networks suitable techniques/simplifications may also need to be carried out, taking account of the nonlinearity of most network equations. Recent work on MES operational analysis has attempted to extend the classical algorithms used for electrical networks to the multi-energy case [100], by also making use of a specific matrix approach that can map conversion devices to locations across different energy networks, suitable for automatic implementations. In particular, in [100] the Newton-Raphson algorithms is used to solve a generalised and detailed set of power flow steady-state equations that in the electricity-heat-gas integrated network case can be summarised as:

$$
\mathbf{F}(\mathbf{x})=\mathbf{0} \Rightarrow\left\{\begin{array}{l}
\leftarrow \text { Active power } \\
\leftarrow \text { Reactive power } \\
\leftarrow \text { Heat power } \\
\leftarrow \text { Loop pressure }- \text { heat } \\
\leftarrow \text { Heat supply temperature } \\
\leftarrow \text { Heat return temperature } \\
\leftarrow \text { Gas flow rate } \\
\leftarrow \text { Loop pressure }- \text { gas }
\end{array}\right.
$$

where $\mathbf{x}$ is the vector of state variables (node voltages and angles for electricity; branch mass flow rate and supply and return nodal temperatures for heat; branch volumetric flow rates for gas). A similar approach can also be found in [101].

As mentioned earlier, the energy hub model allows for a representation of different network interconnections between hubs, also performing an Optimal Power Flow (OPF) considering the multiple energy vectors [91] (see also example in Section V.C). Proposals have also been made to deal with large-scale energy hub formulations by suitable linearization approaches [102].

Several papers in the last decade have specifically dealt with integrated electricity and gas network analysis and optimal power flow, for instance [36] where steady state equations are used. In some cases, specific modelling of the gas network dynamics, using full transient equations [103], may also be necessary, especially when considering large scale networks and high temporal resolution studies, for instance with intraday variations needed to validate flexibility studies [46]. In particular, in these cases it is important that the 
model is able to capture the changes in linepack ${ }^{11}$ that occur in the network and potentially even in specific zones of the network. In fact, the linepack is basically a representation of the physical storage intrinsic in the network which allows buffering of changes between supply and demand (due to market operation, contingencies, etc.) and managing network pressures. (See Fig. 6, taken from [46], for a simplified visual representation of the linepack flexibility in a pipe).

It is also worth pointing out that similar modelling that explicitly takes into account storage intrinsically available in the infrastructure has recently been carried out also for integrated electricity and heat networks, whereby the "slower" dynamics of the heat network are deployed to support power system operation in the presence of wind [104].

Still on the electricity-gas interaction topic, with increasing interest for production of hydrogen from otherwise curtailed renewable electricity and potential for blending it into the gas network in the so-called "power-to-gas" applications already mentioned above, a detailed physical assessment of the gas network characteristics is also needed to estimate the potential for such technology at different times and for different scenarios [32], [33].

\section{E. Data collection and management}

The finer the temporal and spatial scales are, the greater the need is for appropriate values of both the parameters of the system and of independent variables. Many models such as the various implementations of the already mentioned MARKAL/TIMES are so vast that collection and validation of data is a huge challenge; although this task has little value in terms of methodological innovation and hence is often overlooked by academics, result that are meaningful to policy, investors and system operators absolutely depend on it.

In practice, modellers often lack access to much of the required data, because it is commercially confidential (see, for example, [105]), has not been measured (for example, high resolution heat consumption data is not typically available in countries, such as the UK, where heating is prevailingly based on gas), because operational analysis has not (at least so far) been carried out for certain applications (such as in the case of electrical LV networks as well as many gas networks), or because it relates to the future and is highly uncertain. For the last of these, it is common to construct some scenarios that contain sets of assumed values for inputs to a model. These might be chosen to represent forecasts within what is regarded as a 'credible' range, or to test the limits of future decision space. However, as discussed in [106], hindsight can reveal major errors in both of these with the choices made inevitably influenced by opinions that prevailed at the time.

Another practical outcome of access to data is that it often dictates the choices that are made with respect to a model's temporal and spatial scales, irrespective of the modeller's judgement based on the principle discussed above.

\footnotetext{
${ }^{11}$ By definition, the linepack of a pipe is the quantity of gas contained in the pipe at a given time; this is usually measured with respect to the volume at normal temperature and pressure in transient equations [46].
}

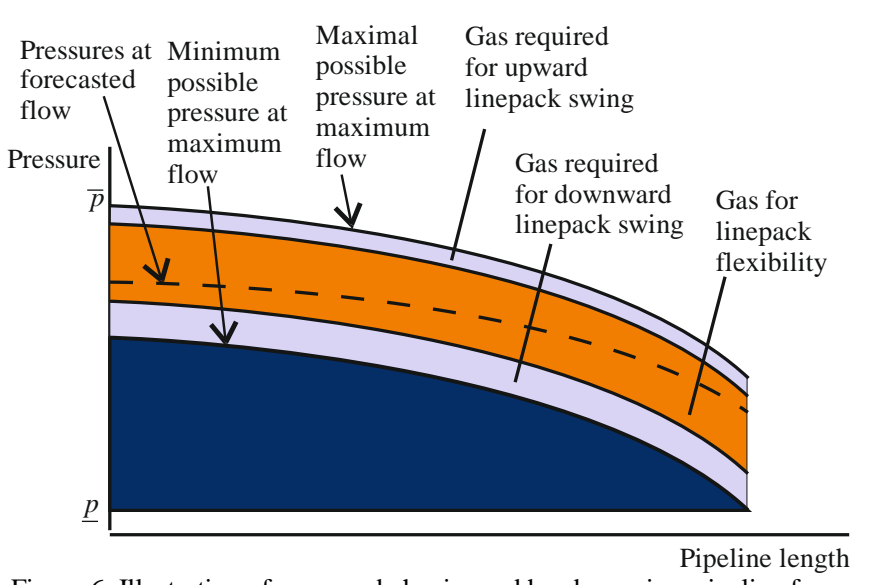

Figure 6. Illustration of pressure behavior and headroom in a pipeline for different flows (taken from [46]).

Luckily, one area where progress can be expected is in the increased deployment of advanced metering infrastructures which promise to provide access to much richer end use data.

\section{F. MES modelling formulation example: whole-energy system planning problem}

To exemplify the potential modelling aspects and challenges in a typical MES problem, let us look at one of the most relevant problems, namely, how to address the quadrilemma from a policy decision maker's perspective. In modelling terms, the problem could be presented as an optimisation problem in which, in recognition of the key concern of affordability, the total cost of the energy system is to be minimised at the planning stage. However, choices should be made about how to represent the other aspects as well, in line with the multi-criteria process outlined above (see Section III.B). In this respect, to date, from a policy perspective, decarbonisation has been presented as a constraint, e.g., a certain percentage of demand for energy to be met from renewable resources by a certain date, a required target for emission reduction, etc. However, that is an indirect representation of the more fundamental challenge that has been quantified by climate scientists: that of restricting global average air temperature rise. Other dimensions of sustainability might be accounted for as actual or pseudo costs added to the objective function. These costs might be such as have been proposed in research on valuation of 'natural capital' or 'ecosystem services' [107], [108]. If insecurity of supply is quantified in terms of 'value of lost load' or 'customer damage functions' [109], this dimension might also be part of the objective function in what becomes, in effect, a weighted multi-criteria problem. However, difficulty in agreeing the parameters of customer damage functions and the nature of political debates about security of supply in many industrialised countries, where the main concern is often about whether security will get any worse than has been experienced in recent years, suggests that it might instead be treated as a constraint. Finally, social acceptability, including impact on comfort $^{12}$, represents perhaps the biggest challenge to

\footnotetext{
${ }^{12}$ To some extent, aspects of reliability can also be considered in terms of comfort and can be put in the context of new contracts and cost functions. (See, for example, [63]).
} 
quantification within a model. In practical terms, the best that might be achievable is to present constraints on the developments of particular technologies, e.g., nuclear power.

On the above premises, practical MES modelling performed with a whole-system view (e.g., country-level) could be framed in broadly the following way, possibly augmented by additional technology-related investment constraints:

$$
J=\min \sum_{y}\left(I_{y}+\sum_{i} R_{y, i}\right)
$$

subject to

$$
\begin{aligned}
& \sum_{y} C_{y} \leq \bar{C} \\
& E\left(U_{y}\right) \leq \bar{U}
\end{aligned}
$$

where:

- $\quad I_{y}$ is the cost of investment in the energy system in year $y$;

- $\quad R_{y, i}$ is the cost of operating the energy system in the $i$ th period of year $y$ including the cost of used natural capital;

- $\quad C_{y}$ is the total mass of carbon emitted by the energy system in year $y$;

- $E\left(U_{y}\right)$ is the expected value of an unreliability index $U$ in year $\mathrm{y}$;

- $\quad \bar{C}$ is a carbon emissions limit;

- $\bar{U}$ is the maximum acceptable value of expected unreliability.

\section{G. Modelling of energy system actors}

A criticism sometimes made of formulations similar to that outlined in the previous section is that, while representing the key priorities, constraints and costs, they adopt what is, in effect, a God-like, perfect-foresight, benign-dictator perspective and fail to represent the pathway-dependent, imperfect-foresight judgements and decisions of actual investors [110]. This is also relevant to the 'socio-economicpolitical' dimension mentioned in Section III.A that goes beyond classical techno-economic engineering modelling. In particular, such formulations are vulnerable to the phenomenon of 'penny switching' in which the model adopts wholesale, to the complete exclusion of a slightly more expensive alternative technology, the slightly cheaper one. In reality, uncertainty about which technology is actually cheapest in the long-run and other features not represented in the model tend to lead to adoption of a mixture of technologies. In an attempt to overcome this limitation, models might be set up with subsets of a particular technology having different costs or with additional constraints included such as limits to the volumes of any one technology that can be added to the system in any one year ('build rate' constraints). For further discussion, see Sections IV and VI.
The main alternative to the idealized, whole-system cost minimization is represented by agent-based approaches such as [111], [112]. While these appear to have some intuitive appeal, in practice there is little that can be regarded as standard good practice with respect to how individual agents are actually represented. In other words, there can considerable variation in how such models are set up and much depends on the modeller's judgement. Such 'distributed' modelling is however very much in line with what we foresee as new families of MES tools (see our 'recommendations' in Section IV).

\section{SOME MES TOOLS}

MARKAL and TIMES models [113] are probably the best known family of tools for whole-energy system studies and have been widely used for policy making worldwide in the last couple of decades. They are generally configured with very little consideration for actual system operational and network infrastructure aspects. This is primarily because they rely on a very detailed bottom-up description of the technical components of the energy system, which requires a significant tradeoff between complexity and tractability, e.g., by adopting national-level technology aggregations and annual or seasonal resolution for (averaged) balance of supply and demand [57], which is unsuitable in a system with RES, storage, etc. (See also the different discussion in Section III).

Several other commercial or freely available tools for energy system analysis have been developed. Some deal with operational aspects, some others with planning or both operation and planning, with obviously different time resolution, simulation windows, analysis scope, objectives (technical, economic, environmental ones), and so forth. However, only a few tools are directly focused on MES aspects, and most of them only cover some of the attributes that are needed to capture the relevant requirements, with very different level of details (e.g., geographical scale, network analysis details, energy vector dimensions, etc.).

It is out of the scope of this work to provide a review of all the (tens of) tools available that have a MES focus, even if to only some extent. However, a number of papers have been published in the last few years which perform good reviews of different tools for different applications relevant to MES modelling. For example, [114] analyses regional-level tools with a focus on integration of RES. Reference [115] reviews tools for community applications and focuses on multigeneration plants. In [116], urban energy systems models are reviewed, similarly to [117], which reviews various MES planning and optimization tools that could be used (even if not specifically designed) for analysis of low carbon urban areas. Similarly, the recent paper [118] reviews energy systems models that have been applied in the UK (with specific details of 22 tools and focus on regional tools for energy policy studies), categorising them considering model purpose and structure, technological detail, and mathematical approach, with attributes including geographical and sectoral scope as well as time horizon and resolution. The already cited [57] provides an excellent review of whole-energy system modelling tools and challenges. 
Table I (taken from [3], to which the reader is referred for details on the reviewed tools) provides some information about a set of well-known MES-relevant tools, with indications of some attributes of importance. Most of these tools are available free of charge (at least for research, academic or teaching purposes), although some need a commercial optimization solver. While the table is not (and is not meant to be) comprehensive, it provides some indications (that are consistent with what found by other researchers in other relevant review papers) as to what MES characteristics one might find in such tools which could be of use. As also discussed in Section VI, it is very likely that for a full scope analysis of MES, more tools would have to be used, and new ones to be developed also based on the identified gaps.

\section{EXAMPLES OF MES MODELLING AND APPLICATIONS}

This Section provides some examples of applications of MES models, tools and thinking from the authors' previous research on relevant topics, also highlighting aspects of particular interest or challenge ${ }^{13}$.

\section{A. Optimal operation and planning of flexible distributed multi-generation plants with thermal storage}

A comprehensive analysis framework and a relevant unified and synthetic Mixed Integer Linear Programming optimization model suitable for evaluating the technoeconomic and environmental characteristics of different Distributed Multi-Generation (DMG) options for district energy systems is presented in [21]. The main characteristics of the case study are discussed below to illustrate the benefits that can be derived from integration of complementary technologies (which creates significant flexibility in the local MES) such as CHP, EHP and Thermal Energy Storage (TES) to locally supply electricity and heat.

The general structure of such a generic plant is illustrated in Fig. 7 (adapted from [87]), whereby an electricity-and-heat DMG system could be characterised by seven ${ }^{14}$ theoretical configurations, namely, \#1: Boiler, \#2: EHP, \#3: EHP +TES, \#4: CHP, \#5: CHP+TES, \#6: CHP+EHP, \#7: $\mathrm{CHP}+\mathrm{EHP}+\mathrm{TES}$. The Case \#1 is also the reference, where electricity is supplied by the grid and heat by gas boilers.

In the case study, the plant is supposed to supply a community of 1000 consumers in the UK, with electricity and heat demand equal to about 900 and $6000 \mathrm{~kW}$, respectively.

The results of the annual studies in terms of operational costs are summarized in Table II, clearly indicating how the more flexible plants (where flexibility is enhanced by adding TES to both CHP only and EHP only, as well as by putting together the complementary CHP and EHP technologies, and finally with the most flexible case being the CHP-EHP-TES one) decrease dramatically the plant operational costs (under the assumption that the plant is exposed to real, time varying

\footnotetext{
13 The examples given here do not contain all the details (assumptions, explanations, etc.) to make them self-sufficient, and the reader interested in such details is invited to read the relevant references.

14 A numerical superscript on the relevant equipment indicates its presence in the corresponding configuration, while components without superscript, such as the AB (Auxiliary Boiler, used for backup) are always present.
}

market prices). Further, Fig. 8 [21] depicts the net present value of the most profitable solutions for a range of discount rates. Again, it can be clearly seen how the most flexible

TABLE I. SOME MES TOOLS AND RELEVANT ANALYSIS ATTRIBUTES (ADAPTED FROM [3])

\begin{tabular}{|c|l|l|l|l|}
\hline & RETScreen & EnergyPlan & DER-CAM & eTransport \\
\hline Operation & Yes & Optimised & Optimised & No \\
\hline Planning & Yes & No & Optimised & Optimised \\
\hline Network & Yes & No & No & Optimised \\
\hline Resolution & Monthly & Hourly & $\begin{array}{l}\text { Hourly/ } \\
\text { Variable }\end{array}$ & Hourly \\
\hline Time scale & Annual & Annual & Lifetime & Lifetime \\
\hline
\end{tabular}

TABLE II. OPERATIONAL COSTS OF DIFFERENT DISTRIBUTED MULTIGENERATION OPTIONS (ADAPTED FROM [21]).

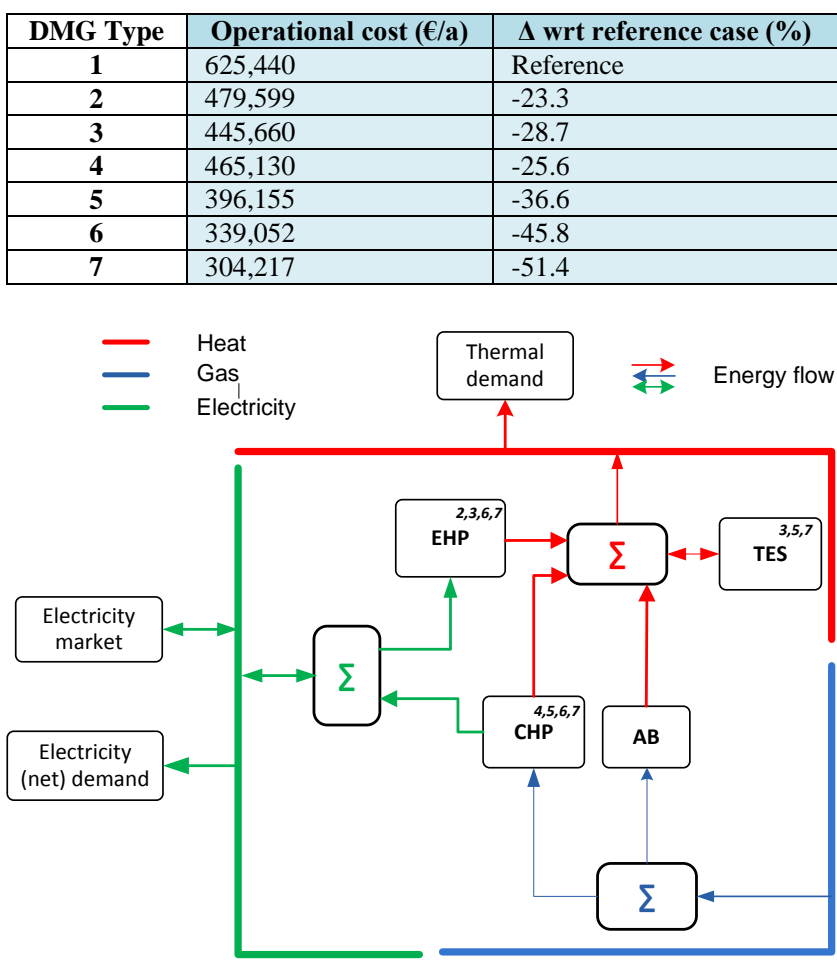

Figure 7. General structure of electricity-and-heat distributed multigeneration plant (adapted from [87]).

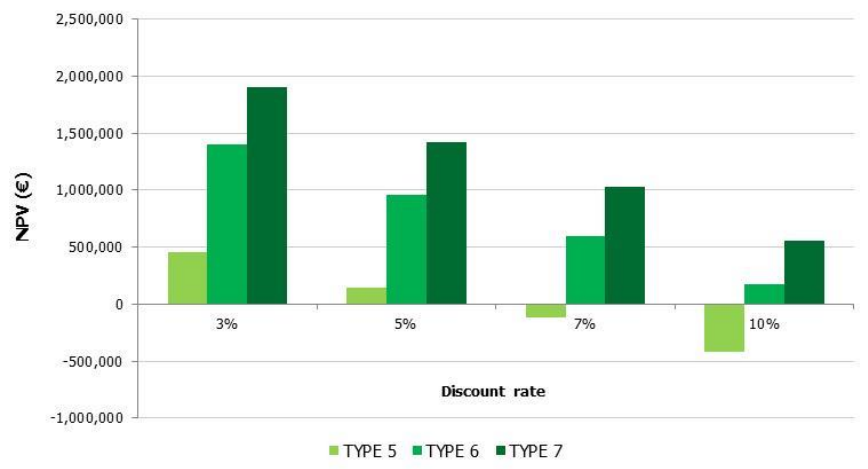

Figure 8. Net Present Value of the most profitable DMG options considered in the case study (adapted from [21]). 
plants are also the most convenient in terms of overall costs, and not only in terms of operational ones. In particular, a positive Net Present Value (NPV) can be achieved in the hybrid cases with CHP and EHP (DMG 6 and DMG 7) even for the higher discount rates and when a CHP-only plant would not be economically viable: this clearly again highlights the economic value of flexibility, and opens the way to developing further future systems where EHPs are coupled to classical CHP plants, to create extremely flexible 'equivalent CHP' or 'virtual CHP' [23], as already mentioned above. Reference [21] (to which the reader is sent for all the details) also discusses how significant primary energy saving and local and global emission reductions can be achieved when considering flexible plants. It has also to be noticed that the benefits of flexibility provided by this type of local MES are likely to increase in future in the presence of more variable sources and with more volatile market prices. Still with respect to this example, in [119] it is also illustrated how the flexibility of such plants may be further deployed in planning by adopting a stochastic optimization methodology for flexible design of the MES system.

\section{B. Real time flexibility from distributed MES}

Further operational flexibility benefits can also be achieved by a distributed MES as in Fig. 9 by the possibility to provide flexibility (basically as a form of real time demand response (DR) to (price) signals) from energy vector switching, as elaborated in [25] (where actually a more complex trigeneration application, with a reversible EHP and an absorption chiller being used to produce cooling too). Taking again the case of Fig. 7, starting from a certain operational condition, for instance optimized based on a dayahead market, the optimal setpoints could be changed in response to a real time signal from the grid. Such a signal could for example be a real time price signal to provide upward reserve to the system operator by reducing the new electricity withdrawn from the grid. Depending on the operational point, this could be achieved by ramping down/switching off the EHP and/or ramping up/switching on the CHP plant, if there is room for that. Details of this can be found in in [25], while [120] also provides a comprehensive discussion on the "timing issue" to provide different flexibility services.

A qualitative example of the results that can be obtained by such operation is illustrated in Fig. 9 [25] in the so-called "profitability map" shown, which is depicted in qualitative form ${ }^{15}$. Specifically, the thick line curve represents the energy cost increase when moving out from the optimal setpoint (for instance based on day-ahead market study) for a given load at a given time, for instance in response to a real-time request to provide flexibility (e.g., reserve) to the system. The cost to provide this flexibility generally increases monotonically with the respect to the flexibility provided (indicated in the picture as reduced electricity input from the grid). The family of dashed lines represents the benefits, parameterised with respect to different DR incentives (each of which assumed here to be expressed in terms of a constant value in monetary

\footnotetext{
${ }^{15}$ Specific quantitative examples as well as the detailed construction of various profitability maps are provided in [25], [120].
}

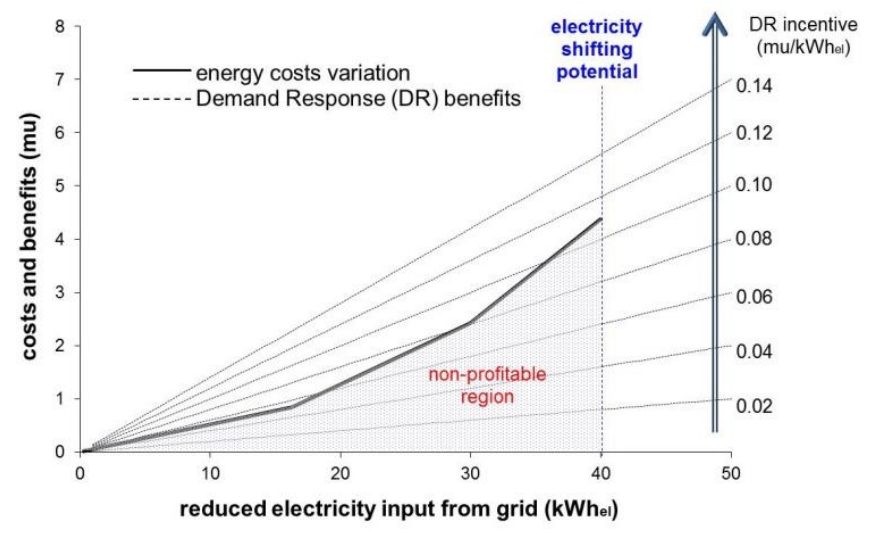

Figure 9. Example of profitability map for real-time demand response (DR) from a distributed multi-generation plant (adapted from [25]).

units (mu) per $\mathrm{kWh}_{\mathrm{el}}$ ), that could be accrued for increasing electricity input reduction (i.e., increasing upward flexibility provided). By comparison of the costs and benefits curves, a non-profitable region can be found for which the demand response incentives are not sufficient to make up for the extra costs in moving from optimal setpoints to provide flexibility. For example, for a provided flexibility of $40 \mathrm{kWh}_{\mathrm{el}}$ (equal to the maximum technically possible, indicated in the figure as "electricity shifting potential"), the profitable flexibility incentives start from $0.11 \mathrm{mu} / \mathrm{kWh}_{\mathrm{e}}$, while for a reduction of $30 \mathrm{kWh}_{\mathrm{el}}$ a DR benefit of $0.08 \mathrm{mu} / \mathrm{kWh}_{\mathrm{el}}$ would already be profitable. Such profitability maps can thus be a powerful tool to carry out a cost-benefit analysis for the flexibility potential for different price incentives under different operating conditions in a MES plant. More details discussing relevant technical and economic aspects of MES flexibility can be found in [25].

Besides the practical illustration of the profitability maps as a powerful decision making tool, the example highlight the flexibility potential of MES to provide, via energy vector shifting, support to power system operation in the form of ancillary services with different time scales (see also [120]) and networks alike, for instance in the form of demand response for post-contingency distribution network capacity provision [121].

\section{Multi-energy optimal power flow in interconnected energy hubs}

In this Section we report an example of multi-energy OPF with the energy hub model (mentioned in Section III.D), taken from [96]. The example refers to the system of Fig. 10, consisting of three equal hubs based on CHP (30\% electrical efficiency, $40 \%$ thermal efficiency) that are interconnected by three independent networks (electricity, district heating and natural gas) and can exchange power with an upstream network (also operating as slack) as well. All networks' multienergy impedances are proportional to the lines' lengths (1-2 $>1-3>2-3$, as from visual inspection), with losses in the electrical system modelled as quadratic functions of the power flows and in the district heating and natural gas systems as cubic functions of the flows. Details of energy prices and cost functions and others are given in [96]. 
Conservation laws and polynomial loss formulae are used for combined optimization of hub-internal and network multienergy flows. A visual example of the OPF results for a snapshot is provided in Fig. 11, with the hub flows (in pu) being for electricity (top), natural gas (middle), and district heating (bottom), and the line width corresponding to the flow magnitude (' $\mathrm{S}$ ' indicates a single aggregate hub).

The optimal dispatch depends on the location in the network, and in the different systems the energy flows are dispatched due to the related loss mechanisms (square/cube of flow). Being connected to the slack node 1 , Hub 1 does not cause network losses, so its optimal supply does not depend on the requirements and network characteristics of the other hubs. Multi-energy flow to Hubs 2 and 3, in contrast, cause network losses. To keep the sum of the squared/cubic losses low, the three energy inputs of Hub 2 and Hub 3 are more balanced than in Hub 1. In terms of flows, Hub 3 is "closer" to the slack node 1 than Hub 2. Hence, Hub 2 consumes less than Hub 3 from the most lossy system, namely, the district heat network. The multi-energy line flows for the same OPF snapshot as in Fig. 11, with again flows in pu and line width corresponding to the flow magnitude, are shown in Fig. 12. More details, including on marginal costs etc., can be found in [96].

The case study clearly illustrates the importance of explicitly modelling simultaneously multi-energy conversion technologies and network characteristics to achieve a thorough and optimal understanding of the energy system as a whole as well as of the individual energy vectors.

\section{Optimal planning of MES portfolios}

In this Section, we report an example of multi-energy portfolio greenfield design model (in the specific case study providing 50\% electricity and 50\% heat) taken from [122], aimed at identifying 'ideal' solutions that could be in principle developed 'from scratch' (not bounded by existing system constraints) and that could therefore be more sustainable in the long run. The conceptual application of such a greenfield approach for future MES design is illustrated in Fig. 13, where firstly an optimal future portfolio (e.g., for the year 2050) is determined, and secondly, 'bridging' portfolios are identified that link the existing energy system to the 'ideal' one via multi-period optimization.

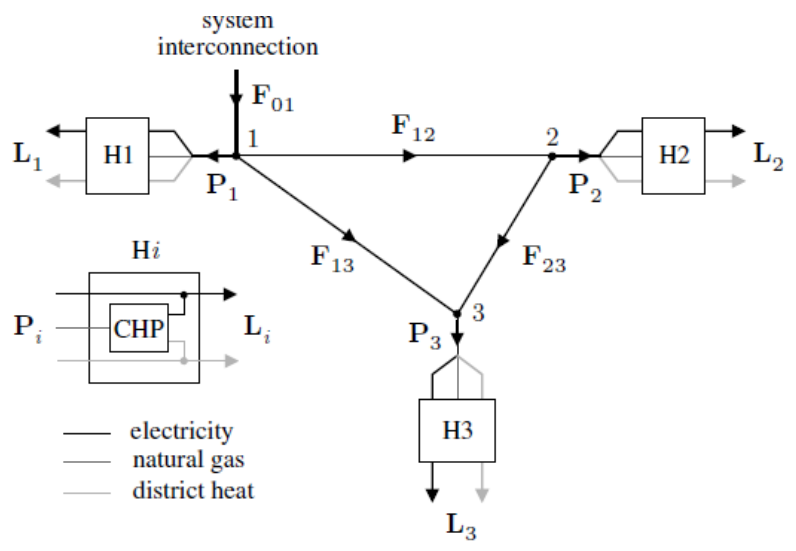

Figure 10. Example with three energy hubs and three networks (taken from [96]).

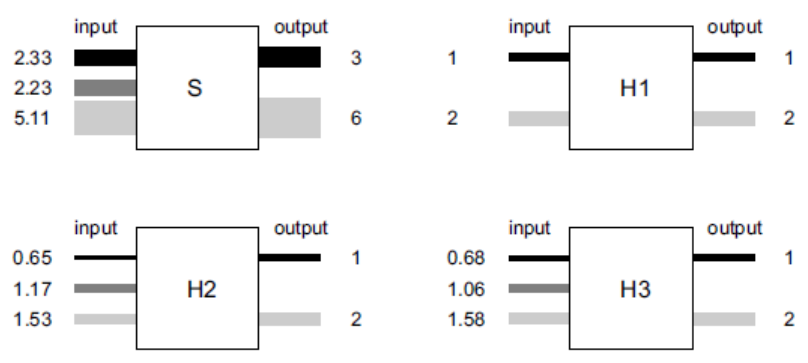

Figure 11. Energy hub flows, with ' $S$ ' indicating the aggregation of the three hubs (taken from [96]).
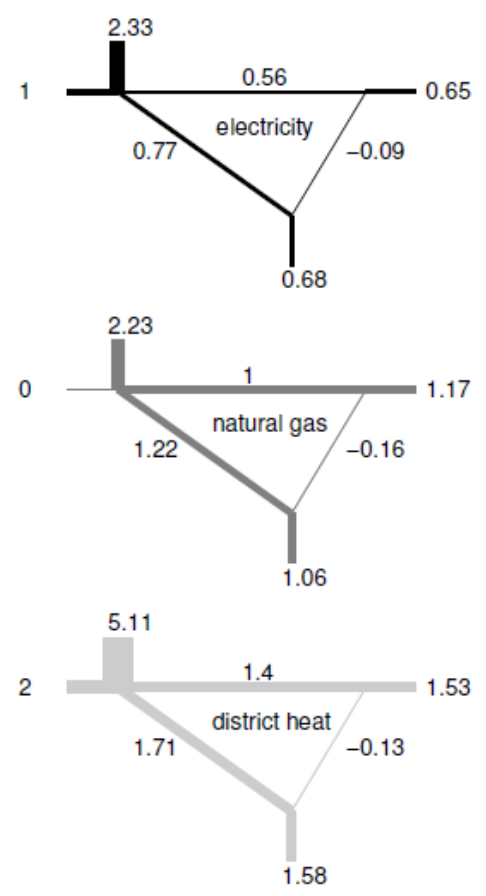

Figure 12. Energy network flows (taken from [96]).

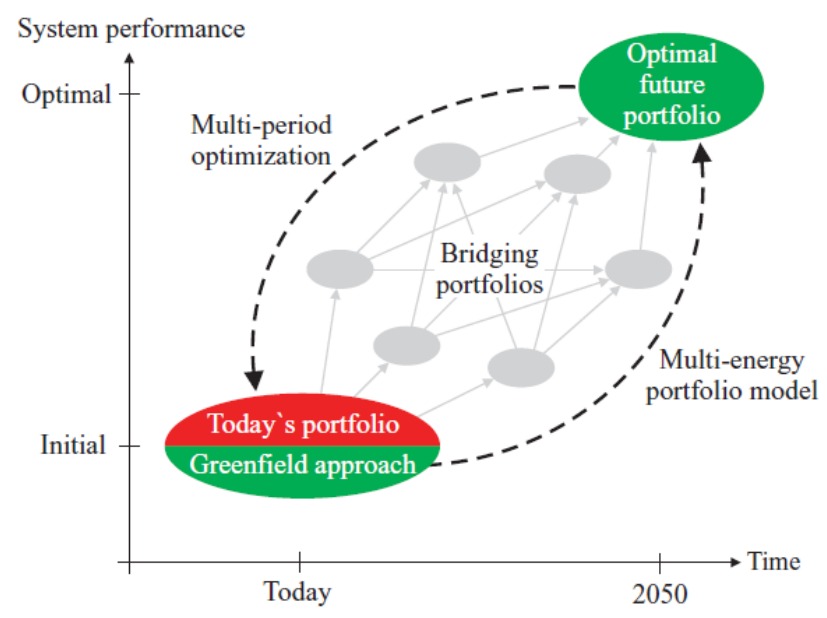

Figure 13. Conceptual illustration of multi-energy greenfield and bridging portfolios for MES planning (taken from [122]). 
Focusing on the optimal greenfield long-term design, a multi-energy version of portfolio theory is used to determine a 'Pareto- efficient' frontier ${ }^{16}$ that links portfolio return rP to the standard deviation of portfolio return $\sigma \mathrm{P}$ (a proxy for risk).

An example of efficient frontier for 2050 for the case study in [122] is shown in Fig. 14, based on a number of available sets of small-scale options for generation Technologies, namely: for electricity only output (T1: PV, T2: wind onshore, and T3: small hydro), electricity and heat outputs (T4: biomass CHP with extraction condensing turbine, and T5: natural gas CHP with extraction condensing turbine), and heat only output (T6: solar thermal collectors, and T7: gas boilers).

The optimal portfolios (shares of technologies $x_{i}$ ) on the efficient frontier corresponding to different risk levels are illustrated in Fig. 15. In order to select one portfolio from the efficient frontier, also the risk preference of the investor should be taken into account, for instance by using a specific utility function. In the considered case study, the efficient portfolio resulting in the highest utility is at a risk level of $\sigma_{P}=$ $0.009 \mathrm{kWh} / \mathrm{Rp}$, corresponding to a portfolio with a relatively low risk. (See [122] for details).

The case study thus illustrates a clear example of approach to MES planning also considering risk and the investor perspective.

\section{E. Integrated electricity and transport analysis}

An example application (taken from [59]) of integrated planning of electricity and (low carbon) transportation systems, with identification of relevant optimal energy policies to be followed, is described in this section.

The case study refers to the Sao Miguel island in Azores and involves EVs with and without Vehicle to Grid (V2G) technology as opposed to conventional Internal Combustion Vehicles (ICVs). The island has a large amount of renewable generation (hydro and in a near future wind power) as well as cogeneration. The generation diagram for 2008 is described in the Fig. 16.

A number of studies were carried out for enhancing the energy sustainability of the São Miguel island system, through a multi-criteria evaluation (see III.B) of RES integration, plus electricity storage, sustainable mobility and the adoption of energy efficiency measures. Different pathways have been considered as described in Fig. 17 as well as Tables III, IV and $\mathrm{V}$, regarding potential portfolio of generation resources (including alternatives for installed capacities), strategy for the transportation sector, and storage solutions, respectively.

TABLE III. RES INSTALLED CAPACITY IN DIFFERENT SCENARIOS (TAKEN FROM [59])

\begin{tabular}{|l|l|l|l|l|}
\hline \multirow{2}{*}{$\begin{array}{c}\text { RES } \\
\text { Pathways }\end{array}$} & \multicolumn{4}{|c|}{ Installed capacity [MW] } \\
\cline { 2 - 5 } Wigh-range & 9 & Hydro & Geothermal & Biomass \\
\hline Mid-range & 9 & 9 & 47 & 10 \\
\hline BAU & 0 & 5 & 37 & 0 \\
\hline
\end{tabular}

\footnotetext{
${ }^{16}$ For mean-variance portfolio optimization, a 'Pareto efficient' portfolio indicates that there are no other portfolios yielding the same or greater expected return and less risk at the same time.
}

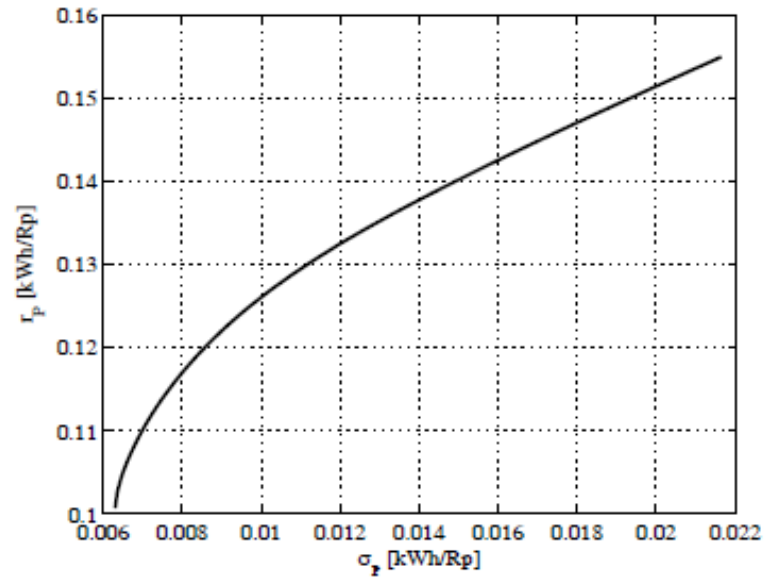

Figure 14. Efficient frontier for year 2050 (taken from [122]) ${ }^{17}$.

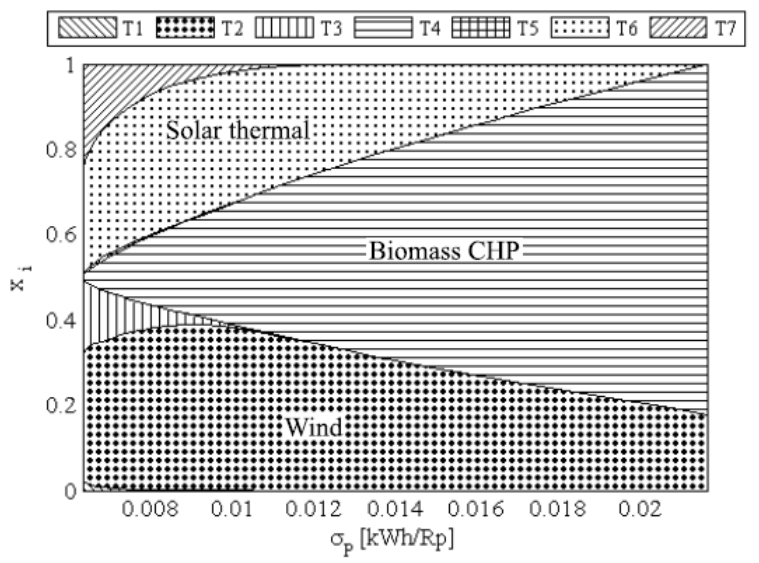

Figure 15. Technology share $\left(x_{i}\right)$ on the 2050 efficient frontier for differen risk levels $\sigma_{P}$ (taken from [122]). Only the three most present technologies are explicitly identified, while the others re indicated in the legenda.

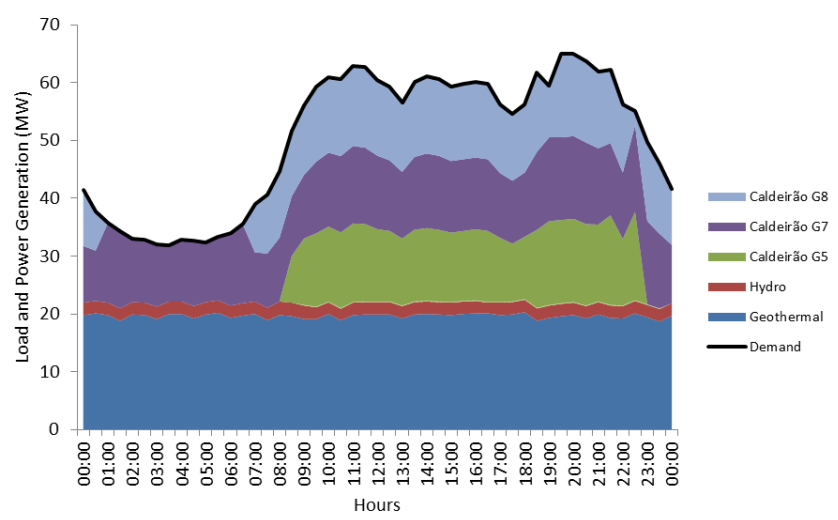

Figure 16. Generation diagram for the Sao Miguel island (taken from [59]).

$17100 \mathrm{Rp}=1 \mathrm{CHF}$ (Swiss Franc) 
TABLE IV. TRANSPORTATION SECTOR SCENARIOS (TAKEN FROM [59])

- Strategy based on efficient ICVs, biofuels and behavioural change

- Strategy based on the introduction of 5000 EVs (i.e. 7,5\% of light vehicles fleet)

- Strategy based on the introduction of 10000 EVs (i.e. $15 \%$ of light vehicles fleet)

TABLE V. ALTERNATIVE ELECTRICITY STORAGE SOLUTIONS (TAKEN FROM [59])

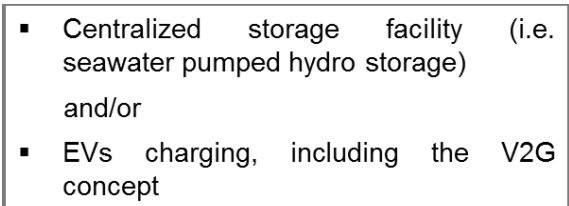

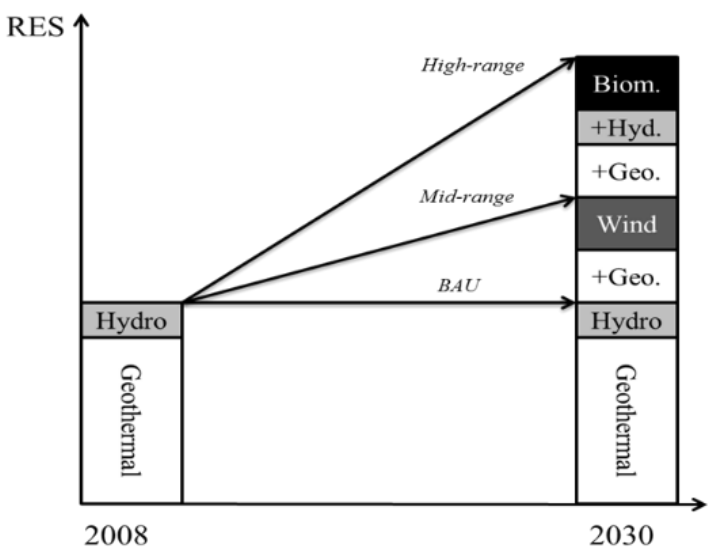

Figure 17. Possible energy pathways for the Sao Miguel case study (taken from [59]).

TABLE VI. CASE STUDY FEASIBLE ALTERNATIVES (TAKEN FROM [59]).

\begin{tabular}{|c|c|c|c|c|c|c|}
\hline $\begin{array}{c}\text { Energy } \\
\text { Efficient } \\
\text { Measures } \\
\text { on the Load }\end{array}$ & $\begin{array}{l}\text { Renewable } \\
\text { Energy } \\
\text { Increase }\end{array}$ & $\begin{array}{c}\text { Efficient ICVs, } \\
\text { biofuels and } \\
\text { Behavioural change }\end{array}$ & $\begin{array}{l}\text { Electric mobiity } \\
\text { (number of EVs) }\end{array}$ & $\begin{array}{c}\text { Centralized Storage } \\
\text { (Installed Capacity } \\
\text { of Pumped Hydro } \\
\text { Storage) }\end{array}$ & $\begin{array}{l}\text { Vehicle-to- } \\
\text { Grid }\end{array}$ & $\begin{array}{l}\text { Alternative } \\
\text { number }\end{array}$ \\
\hline \multirow{18}{*}{ NO } & \multirow{6}{*}{ High-range } & \multirow{2}{*}{ YES } & \multirow{2}{*}{ No (0 EVs) } & Yes $(20 \mathrm{MW})$ & \multirow{2}{*}{ No } & 1 \\
\hline & & & & No $(0 \mathrm{MW})$ & & 2 \\
\hline & & \multirow{4}{*}{ NO } & \multirow{2}{*}{ Yes $(10,000 \mathrm{EVs})$} & \multirow{2}{*}{ No $(0 \mathrm{MW})$} & Yes & 3 \\
\hline & & & & & No & 4 \\
\hline & & & \multirow{2}{*}{ Yes $(5,000 \mathrm{EVs})$} & \multirow{2}{*}{ Yes (20 MW) } & Yes & 5 \\
\hline & & & & & No & 6 \\
\hline & \multirow{6}{*}{ Mid-range } & \multirow{2}{*}{ YES } & \multirow{2}{*}{ No (0 EVs) } & Yes $(20 \mathrm{MW})$ & \multirow{2}{*}{ No } & 7 \\
\hline & & & & No $(0 \mathrm{MW})$ & & 8 \\
\hline & & \multirow{4}{*}{ NO } & \multirow{2}{*}{ Yes $(10,000 \mathrm{EVs})$} & \multirow{2}{*}{ No $(0 \mathrm{MW})$} & Yes & 9 \\
\hline & & & & & No & 10 \\
\hline & & & \multirow{2}{*}{ Yes $(5,000 \mathrm{EVs})$} & \multirow{2}{*}{ Yes (20 MW) } & Yes & 11 \\
\hline & & & & & No & 12 \\
\hline & \multirow{6}{*}{ BAU } & \multirow{2}{*}{ YES } & \multirow{2}{*}{ No (0 EVs) } & Yes (20 MW) & \multirow{2}{*}{ No } & 13 \\
\hline & & & & No $(0 \mathrm{MW})$ & & 14 \\
\hline & & \multirow{4}{*}{ NO } & \multirow{2}{*}{ Yes $(10,000 \mathrm{EVs})$} & \multirow{2}{*}{ No (0 MW) } & Yes & 15 \\
\hline & & & & & No & 16 \\
\hline & & & \multirow{2}{*}{ Yes $(5,000 \mathrm{EVs})$} & \multirow{2}{*}{ Yes (20 MW) } & Yes & 17 \\
\hline & & & & & No & 18 \\
\hline
\end{tabular}

The feasible alternatives considered in the study are described in the Table VI.

The main conclusions that were derived after analyzing the alternatives and considering total costs, total $\mathrm{CO} 2$ emissions and reliability as multi-criteria to assess the integrated electricity-transport system led to the following main conclusions:

- Environmental benefits of RES were ratified;

- $\quad$ Energy efficiency measures lead to lower total annual costs and emissions;

- $\quad$ Electric mobility can be cost-competitive, but only in the case when load decreases;

- $\quad$ Electric mobility is environmentally competitive for large amounts of RES and high EVs rollout;

- $\quad \mathrm{V} 2 \mathrm{G}$ is only environmentally beneficial in case of large amounts of RES;
- Centralized storage is more attractive (economically and environmentally), if energy efficiency measures are not applied at the load level.

The last four points, in particular, highlights the importance of an integrated analysis of the electricity and transport sectors, explicitly considering the technologies involved in the MES analysis. These results will help the decision agent to decide with additional stakeholder's information on the path to follow, fostering the concept of energy systems integration.

\section{F. System level assessment of integrated electricity and gas network operation in low carbon MES}

In the context of provision of flexibility in low carbon power systems with larger shares of RES, it is likely that gas turbines will play a key role in providing short-term balancing in many countries. However, there may be physical (as well as economic) limitations as to how much flexibility the gas network could actually provide. Further, in those cases where gas is also used as a prominent energy vector for heating, such 
as in the UK, there is a need for considering low carbon heating options as well and the interplay with the low carbon power systems, in a true system level MES framework that also explicitly considers network infrastructure constraints. Such a study has been for instance carried out in [46], where, through an integrated model that combines both electrical DC OPF and both steady-state and transient gas analyses, it is shown how changes to the heating sector can impact on the MES combined flexibility requirements and capability, and quantified how the electrical network can experience local constraints due to the gas network's lack of flexibility. Some results from the case studies in [46], relevant to the Great Britain electrical and gas transmission system, are reported in Fig. 18 and Fig. 19. More specifically, Fig. 18 depicts the year-round duration curve of the net load changes over two hours for the two considered heating scenarios, namely, one based on gas (as currently) and one based on electrified heating. The results indicate a maximum 54\% (resp. 78\%) increase in the maximum upward (resp. downward) two hour ramps to be picked up by balancing generators. Further, Fig. 19 illustrates, in a scenario with high penetration of solar PV, how the combined impact of the evening reduction in solar production and the increased electricity (peak) demand due to an electrified heating sector (Fig. 19.b) results in many ramps of much greater magnitude and length than in a gas based system (Fig. 19.a). These may cause flexibility issues, especially in the case of shortage of "zonal linepack" in the gas network, as expanded on in [46].

The examples here thus clearly illustrate the need for carrying out MES analysis with multiple sectors (electricity/heat/gas) and relevant technologies, explicit consideration for multiple energy network modelling, and multi-temporal assessment (with different time resolutions for the electricity and gas network models).

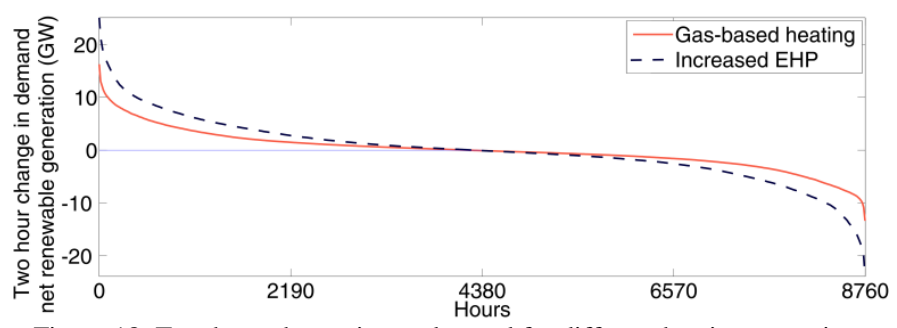

Figure 18. Two hour change in net demand for different heating scenarios (taken from [46]).

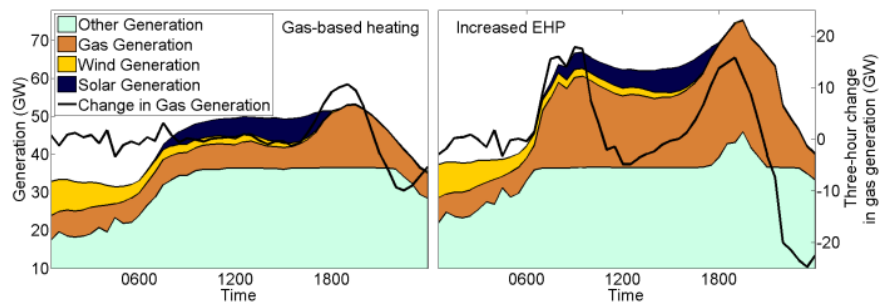

(a)

(b)

Figure 19. Combined impact of heating technologies and solar PV on gas generators' ramps for (a) Gas-based scenario and (b) Increased EHP scenario (taken from [46]).

\section{GAPS AND OPPORTUNITIES}

From the discussions and analysis reported above and the works that were reviewed, it emerges that there are many opportunities for research and for models/tool development in the area of MES, whose interest and importance will grow with the increasing interaction of the electrical smart grid with other energy sectors, also fostered by electrification.

Paraphrasing a famous quote of H. L. Mencken ${ }^{18}$, one might say: "For every complex problem there is an answer that is clear, simple, and wrong". By this, we do not mean of course that the current models and tools are 'simple', but rather that there is quite some way to go to deal with the full complexity of MES problems. In fact, one of the issues we have found is the lack of tools that adequately consider both time and space (including network representation) aspects, with relevant temporal and spatial resolutions and energy network modelling details (e.g., with gas transient equations), in MES. This can thus represent a key research opportunity, especially considering the importance of storage (for which suitable temporal resolutions are needed) and of quantifying to what extent new multi-energy infrastructure is actually needed or could be partly displaced by smarter operation of the whole energy system. In addition, it is crucial to warn that current tools may be biased towards certain technologies and in many cases overestimate the benefits of particular solutions/scenarios due to the lack of modelling of certain aspects, again most noticeably high temporal resolution as well as spatial/infrastructure consideration. Further, in some cases even when a seemingly high temporal resolution (e.g., one hour) is used by a specific tool, it is arguable how realistically (power) system operation is captured, e.g., in respect of frequency response and reserves, etc. This aspect again becomes even more important to consider in the presence of various flexibility options that could be provided by multi-energy resources, including demand side and storage.

An associated relevant, burning open issue is that of representation of operational aspects in planning, which somehow brings together the previous considerations of temporal and spatial resolutions, network representation, system operation representation, and interlinked tools. In fact, if this issue is challenging for power systems only, when considering the interaction of multiple energy sectors the complexity is multiplied and suitable approaches for system reductions, decompositions, etc., are needed.

It is clear that, due to the sheer complexity and size of the problems themselves, developing new and more suitable MES modelling approaches and tools is particularly challenging. In particular, there is intrinsic difficulty in including everything in 'one' model or tool. This brings about the important question of dependency on a suite of models that need to be made to work together. This represents a key area of computational research (see, e.g., [123]), namely, to understand how existing models can be linked together to ensure that the whole energy system is finally represented correctly, and how new models should be designed to make it

${ }^{18}$ H. L. Mencken, "Explanations exist; they have existed for all time; there is always a well-known solution to every human problem - neat, plausible, and wrong", https://en.wikiquote.org/wiki/H._L._Mencken. 
happen. In the light of improving our planning models with operational characteristics, there is a relatively new area that is emerging, namely, resilience ${ }^{19}$ sSee [41] for a general framework and [125], [126] for comprehensive surveys of the state of the art). In this context, it would for instance be interesting to understand how specific MES could make a system more resilient, especially at a distributed level (e.g., through MES microgrid applications), and it is currently an open research question as to whether an integrated MES is more reliable and resilient than alternative options, such as the current situation or a 'fully electric' energy system. On the other hand there is the important resilience issue of the interdependency of infrastructure itself (see, e.g., gas and electricity [127], or water and electricity [128]), that requires much more research work.

Another research area that we see as particularly appealing to energy system modellers is that of inclusion of uncertainty in MES operation and planning. Given the complexity of the problem, most models and tools so far have focused on deterministic analysis, possibly using sensitivities to deal with uncertainty (see, for example, [13] for a trigeneration planning model), and with few cases working out suitable techniques for modelling uncertainty in operation (see, for example, [28] for an integrated electricity and heat active network management tool that adopts rolling scheduling/dispatch horizons to account for uncertainty in RES in-feed) or planning (see, for example: [129], using a real option approach for a distributed multi-generation plant planning; [130], using portfolio theory for MES generation-transmission planning; or [119], using stochastic optimization for flexible planning of multi-energy generation plants). There is thus great room to do research in this area, also possibly introducing risk criteria and decision theory techniques [131] in the assessment.

Another open question is, in our opinion, that of performance criteria: do we have the right methodologies/metrics to assess MES? In fact, historically systems have been planned independently and classical multicriteria metrics, depending on the specific type of analysis, have been used. These have been discussed in Section III.B including relevant specific criteria such as primary energy saving for multi-generation plants etc. However, it is unclear whether such criteria are adequate to capture the complexity of energy systems integration (see, for example, [132]), and new views on these aspects are welcome.

Last but not least, innovation and new technology deployment happen because there is some form of underlying positive business case. In particular, when talking about MES, especially in whole-energy system studies, the whole energy value chain (from energy production to usage) in multiple energy sectors is involved, and so are relevant market and regulated actors. Moreover, the distributed nature of many MES technologies and set-ups substantially breaks the classical "linear" power system value chain from centralised thermal generation to consumption, further adding complexity.

\footnotetext{
19 There are several definitions of resilience, for instance the one by Overbye et al. [124] as "the ability to degrade gradually under increasing system stress and then to recover to its pre-disturbance secure state".
}

There is therefore a need to develop new business models to make MES innovation happen (see, for example, [26]), accompanied by adequate market reforms and regulatory changes. Once again, this opens up a new and stimulating area of research.

A very last practical note has also to do with data and case studies. As mentioned in Section III.E, in many cases data for MES analysis are represented by a huge set that is often not easy to critically scrutinize; hence, in many cases one may end up 'accepting' what is contained perhaps as default in some tools even though they may be out of date, inconsistent or based on questionable judgement. In other cases, suitable data are just not available (this is for instance the case of multienergy network test cases again mentioned earlier). Therefore, it would certainly be of interest and importance to both collect new relevant information/data and critically analyse existing sets.

\section{CONCLUSIONS AND RECOMMENDATIONS}

In this paper, we have provided a modelling-oriented overview of the emerging concept of integration of multiple energy systems. Drivers and need for, as well as challenges and opportunities in modelling of MES have been highlighted. Such modelling should be capable of assessing interactions between different energy sectors, vectors and networks, with the aim of bringing out the benefits and potential unforeseen or undesired drawbacks arising from energy systems integration at both operational and planning stages. Aspects such as choices to be made with respect to spatial and temporal scales and resolutions, network representation and system operational details, links between existing models and between operational and planning aspects, and general mathematical frameworks have been discussed. The concepts discussed and potential applications have been illustrated through various MES examples from the authors' experience.

Challenges, gaps and opportunities in MES modelling have been discussed to provide relevant insights to engage modellers in developing a new range of analytical capabilities that we believe are needed to deal with the complexity of MES. In fact, following Krakauer's definition of complex systems as those that "do not yield to compact forms of representation" 20 , future systems are definitely more complex than in the past, and the question is to what extent modellers can and need to represent them in a more or less suitable fashion, without missing critical aspects in the trade-off between simplicity and accuracy. As mentioned in [57], this is not only relevant to the 'mathematics' of modelling per se, but also and perhaps most importantly to its practicalities: overly complex models and tools may have the drawbacks of rapidly decreasing marginal benefits, higher and higher maintenance cost, increasing difficulty in managing their (distributed) growth, and vulnerability to unexpected 'shocks'. Further, the data that are needed, across different scales and appropriate resolutions, may be computationally unmanageable in most cases. Somehow, this is what we are already seeing today with some well-known 'classical' tools.

\footnotetext{
${ }^{20}$ D. Krakauer, Lectures, available https://www.complexityexplorer.org/.
} 
As from all the discussions throughout the paper, the emerging requirements in MES modelling thus call for (a set of) tools that are able to capture complex system operation and network constraints and bring in the need for involving more power systems engineers and researchers into MES modelling that has hitherto often been performed by economists or technology policy specialists. Therefore, also taking into account that the key underlying challenge in MES research is its inter-disciplinary dimension (ranging from power system operation to thermal network analysis to economics, energy externality, and social sciences), research groups, centres, departments and consortia with multiple sets of expertise, rather than individuals, should tackle this new area of research, with the further need for updating existing university teaching curricula. This should also be reflected in the development of new families of, possibly open-source and data-transparent, flexible tools rather than a 'big' one, for which standards of interactions and compatibility as well as 'big data' management become critical too.

\section{ACKNOWLEDGMENTS}

The authors would like to thank the Power Systems Computation Conference (PSCC) Steering Committee for the invitation to write this paper. PM would also like to acknowledge the UK EPSRC and the HubNet project for the support provided to carry out this research.

\section{REFERENCES}

[1] J. A. Sautter, J. Landis, and M. H. Dworkin, "The energy trilemma in the green mountain state: An analysis of Vermont's energy challanges and policy options," Vermont J. Environ. Law, vol. 10, pp. 478-506, 2010.

[2] S. Graham, "Only efficiency can solve the energy "quadrillema," Business Green, 18 November 2013. [Online]. Available: http://www.businessgreen.com/bg/opinion/2306739/only-efficiencycan-solve-the-energy-quadrillema.

[3] P. Mancarella, "MES (multi-energy systems): An overview of concepts and evaluation models," Energy, vol. 65, pp. 1-17, Feb. 2014.

[4] G. Strbac, M. Aunedi, D. Pudjianto, P. Djapic, S. Gammons, and R. Druce, "Understanding the Balancing Challenge, Report for the Department of Energy and Climate Change," London, UK, August 2012.

[5] M. O'Malley and B. Kroposki, "Energy comes together," IEEE Power \& Energy Magazine, 2013.

[6] D. J. C. MacKay, Sustainable Energy - without the hot air. Cambridge: UIT Cambridge, 2008. [Online]. Available: https://www.withouthotair.com/

[7] P. Mancarella and G. Chicco, Distributed multi-generation systems. Energy models and analyses. New York: Nova Science Publishers, 2009.

[8] G. Chicco and P. Mancarella, "Distributed multi-generation: A comprehensive view," Renew. Sustain. Energy Rev., vol. 13, no. 3, pp. 535-551, Apr. 2009.

[9] P. Mancarella, "From cogeneration to trigeneration: energy planning and evaluation in a competitive market framework," $\mathrm{PhD}$ Thesis, Politecnico di Torino, Torino, Italy, April 2006.

[10] G. Chicco and P. Mancarella, "Trigeneration primary energy saving evaluation for energy planning and policy development," Energy Policy, vol. 35, no. 12, pp. 6132-6144, Dec. 2007.

[11] G. Chicco and P. Mancarella, "Assessment of the greenhouse gas emissions from cogeneration and trigeneration systems. Part I: Models and indicators," Energy, vol. 33, no. 3, pp. 410-417, Mar. 2008.

[12] P. Mancarella and G. Chicco, "Assessment of the greenhouse gas emissions from cogeneration and trigeneration systems. Part II: Analysis techniques and application cases," Energy, vol. 33, no. 3, pp. 418-430, Mar. 2008.
[13] G. Chicco and P. Mancarella, "From Cogeneration to Trigeneration: Profitable Alternatives in a Competitive Market," IEEE Trans. Energy Convers., vol. 21, no. 1, pp. 265-272, Mar. 2006.

[14] International Energy Agency, "World Energy Outlook 2015," 2015.

[15] D. Brkić and T. I. Tanasković, "Systematic approach to natural gas usage for domestic heating in urban areas," Energy, vol. 33, no. 12, pp. 1738-1753, Dec. 2008.

[16] B. H. Bakken, H. I. Skjelbred, and O. Wolfgang, "eTransport: Investment planning in energy supply systems with multiple energy carriers," Energy, vol. 32, no. 9, pp. 1676-1689, Sep. 2007.

[17] P. Meibom, J. Kiviluoma, R. Barth, H. Brand, C. Weber, and H. V. Larsen, "Value of electric heat boilers and heat pumps for wind power integration," Wind Energy, vol. 10, no. 4, pp. 321-337, Jul. 2007.

[18] B. Mathiesen and H. Lund, "Comparative analyses of seven technologies to facilitate the integration of fluctuating renewable energy sources," IET Renew. Power Gener., vol. 3, no. August 2008, pp. 190-204, 2009.

[19] X. Chen, C. Kang, M. O’Malley, Q. Xia, J. Bai, C. Liu, R. Sun, W. Wang, and $\mathrm{H}$. $\mathrm{Li}$, "Increasing the Flexibility of Combined Heat and Power for Wind Power Integration in China: Modeling and Implications," IEEE Trans. Power Syst., vol. 30, no. 4, pp. 1848-1857, Jul. 2015.

[20] M. B. Blarke and H. Lund, "The effectiveness of storage and relocation options in renewable energy systems," Renew. Energy, vol. 33, no. 7, pp. 1499-1507, Jul. 2008.

[21] T. Capuder and P. Mancarella, "Techno-economic and environmental modelling and optimization of flexible distributed multi-generation options," Energy, vol. 71, pp. 516-533, Jul. 2014.

[22] M. B. Blarke and E. Dotzauer, "Intermittency-friendly and highefficiency cogeneration: Operational optimisation of cogeneration with compression heat pump, flue gas heat recovery, and intermediate cold storage," Energy, vol. 36, no. 12, pp. 6867-6878, 2011.

[23] P. Mancarella, "Cogeneration systems with electric heat pumps: Energy-shifting properties and equivalent plant modelling," Energy Convers. Manag., vol. 50, no. 8, pp. 1991-1999, Aug. 2009.

[24] Y. Kitapbayev, J. Moriarty, and P. Mancarella, "Stochastic control and real options valuation of thermal storage-enabled demand response from flexible district energy systems," Appl. Energy, vol. 137, pp. 823831, Jan. 2015.

[25] P. Mancarella and G. Chicco, "Real-Time Demand Response From Energy Shifting in Distributed Multi-Generation," IEEE Trans. Smart Grid, vol. 4, no. 4, pp. 1928-1938, Dec. 2013.

[26] N. Good, E. A. Martínez Ceseña, L. Zhang, and P. Mancarella, "Techno-economic assessment and business case modelling of low carbon technologies in distributed multi-energy systems," Appl. Energy, 2016;167:158-72.

[27] N. Good and P. Mancarella, "Modelling and assessment of business cases for smart multi-energy districts," in Proc. 2016 19th Power Systems Computation Conference (PSCC), in press.

[28] A. Saint-Pierre and P. Mancarella, "Integrated Electricity and Heat Active Network Management," in Proc. 2016 19th Power Systems Computation Conference (PSCC), in press.

[29] M. Qadrdan, M. Abeysekera, M. Chaudry, J. Wu, and N. Jenkins, "Role of power-to-gas in an integrated gas and electricity system in Great Britain," Int. J. Hydrogen Energy, vol. 40, no. 17, pp. 57635775, 2015.

[30] G. Gahleitner, "Hydrogen from renewable electricity: An international review of power-to-gas pilot plants for stationary applications," Int. J. Hydrogen Energy, vol. 38, no. 5, pp. 2039-2061, Feb. 2013.

[31] S. Schiebahn, T. Grube, M. Robinius, V. Tietze, B. Kumar, and D. Stolten, "Power to gas: Technological overview, systems analysis and economic assessment for a case study in Germany," Int. J. Hydrogen Energy, vol. 40, no. 12, pp. 4285-4294, Apr. 2015.

[32] S. Clegg and P. Mancarella, "Integrated Modeling and Assessment of the Operational Impact of Power-to-Gas (P2G) on Electrical and Gas Transmission Networks," IEEE Trans. Sustain. Energy, vol. 6, no. 4, pp. 1234-1244, Oct. 2015.

[33] S. Clegg and P. Mancarella, "Storing renewables in the gas network: modelling of power-to-gas seasonal storage flexibility in low-carbon power systems," IET Gener. Transm. Distrib., vol. 10, no. 3, pp. 566575, Feb. 2016 
[34] M. Chaudry, N. Jenkins, and G. Strbac, "Multi-time period combined gas and electricity network optimisation," Electr. Power Syst. Res., vol. 78, no. 7, pp. 1265-1279, Jul. 2008.

[35] M. Qadrdan, J. Wu, N. Jenkins, and J. Ekanayake, "Operating Strategies for a GB Integrated Gas and Electricity Network Considering the Uncertainty in Wind Power Forecasts," IEEE Trans. Sustain. Energy, vol. 5, no. 1, pp. 128-138, Jan. 2014.

[36] Cong Liu, M. Shahidehpour, Yong Fu, and Zuyi Li, "SecurityConstrained Unit Commitment With Natural Gas Transmission Constraints," IEEE Trans. Power Syst., vol. 24, no. 3, pp. 1523-1536, Aug. 2009.

[37] A. Alabdulwahab, A. Abusorrah, X. Zhang, and M. Shahidehpour, "Coordination of Interdependent Natural Gas and Electricity Infrastructures for Firming the Variability of Wind Energy in Stochastic Day-Ahead Scheduling," IEEE Trans. Sustain. Energy, vol. 6, no. 2, pp. 606-615, Apr. 2015.

[38] Seungwon An, Qing Li, and T. W. Gedra, "Natural gas and electricity optimal power flow," in 2003 IEEE PES Transmission and Distribution Conference and Exposition, 2003, vol. 1, pp. 138-143.

[39] M. Chaudry, N. Jenkins, M. Qadrdan, and J. Wu, "Combined gas and electricity network expansion planning," Appl. Energy, vol. 113, pp. 1171-1187, Jan. 2014.

[40] X. Zhang, M. Shahidehpour, A. Alabdulwahab, and A. Abusorrah, "Optimal Expansion Planning of Energy Hub With Multiple Energy Infrastructures," IEEE Trans. Smart Grid, vol. 6, no. 5, pp. 2302-2311, Sep. 2015.

[41] M. Panteli and P. Mancarella, "The Grid: Stronger, Bigger, Smarter?: Presenting a Conceptual Framework of Power System Resilience," IEEE Power Energy Mag., vol. 13, no. 3, pp. 58-66, May 2015.

[42] A. L. . Syrri, E. A. Martinez Cesena, and P. Mancarella, "Contribution of Microgrids to distribution network reliability," in 2015 IEEE Eindhoven PowerTech, 2015, pp. 1-6.

[43] S. D. Manshadi and M. E. Khodayar, "Resilient Operation of Multiple Energy Carrier Microgrids," IEEE Trans. Smart Grid, vol. 6, no. 5, pp. 2283-2292, Sep. 2015

[44] T. Li, M. Eremia, and M. Shahidehpour, "Interdependency of Natural Gas Network and Power System Security," IEEE Trans. Power Syst., vol. 23, no. 4, pp. 1817-1824, Nov. 2008.

[45] M. Shahidehpour, Yong Fu, and T. Wiedman, "Impact of Natural Gas Infrastructure on Electric Power Systems," Proc. IEEE, vol. 93, no. 5, pp. 1042-1056, May 2005.

[46] S. Clegg and P. Mancarella, "Integrated Electrical and Gas Network Flexibility Assessment in Low-Carbon Multi-Energy Systems," IEEE Trans. Sustain. Energy, vol. 7, no. 2, pp. 718-731, Apr. 2016.

[47] G. E. P. Box and N. R. Draper, Empirical Model-Building and Response Surfaces. Wiley, 1987, p. 424.

[48] A. Ahmed and P. Mancarella, "Strategic techno-economic assessment of heat network options for distributed energy systems in the UK," Energy, vol. 75, pp. 182-193, Oct. 2014.

[49] L. G. Fishbone and H. Abilock, "Markal, a linear-programming model for energy systems analysis: Technical description of the bnl version," Int. J. Energy Res., vol. 5, no. 4, pp. 353-375, 1981.

[50] R. Loulou and M. Labriet, "ETSAP-TIAM: the TIMES integrated assessment model Part I: Model structure," Comput. Manag. Sci., vol. 5, no. 1-2, pp. 7-40, Feb. 2008

[51] S. Rossiter, J. Noble, and K. R. W. Bell, "Social Simulations: Improving Interdisciplinary Understanding of Scientific Positioning and Validity," J. Artif. Soc. Soc. Simul., vol. 13, no. 1, pp. 661-673, Apr. 2010.

[52] G. Westner and R. Madlener, "Development of cogeneration in Germany: A mean-variance portfolio analysis of individual technology's prospects in view of the new regulatory framework," Energy, vol. 36, no. 8, pp. 5301-5313, Aug. 2011.

[53] P. Mancarella, C. K. Gan, and G. Strbac, "Fractal model for ElectroTherma Network Studies," Presented at 17th Power Systems Computation Conference (PSCC), Stockholm, Sweden, 2011. [Online]. Available:http://www.pscccentral.org/uploads/tx_ethpublications/fp515.pdf

[54] A. Saint-Pierre and P. Mancarella, "Active Distribution System Management: A Dual-Horizon Scheduling Framework for DSO/TSO Interface Under Uncertainty," IEEE Trans. Smart Grid, pp. 1-12, 2016.
[55] P. Dodds, "Assessing the need for low-carbon technologies using an energy systems approach," Glasgow, 2016.

[56] E. Carpaneto, G. Chicco, P. Mancarella, and A. Russo, "Cogeneration planning under uncertainty: Part I: Multiple time frame approach," Appl. Energy, vol. 88, no. 4, pp. 1059-1067, Apr. 2011.

[57] S. Pfenninger, A. Hawkes, and J. Keirstead, "Energy systems modeling for twenty-first century energy challenges," Renew. Sustain. Energy Rev., vol. 33, pp. 74-86, May 2014.

[58] F. Li, "Spatially explicit techno-economic optimisation modelling of UK heating futures," $\mathrm{PhD}$ thesis, University College London, London, UK, 2013.

[59] A. M. L. M. Da Silva, "Energy Planning With Electricity Storage and Sustainable Mobility: the Study of an Isolated System Phd Program in Sustainable Energy Systems," PhD Thesis, Faculty of Engineering of Porto University, January 2013.

[60] J. H. Horlock, Cogeneration--combined Heat and Power (CHP). FL: Krieger, 1997.

[61] M. V. Biezma and J. R. S. Cristóbal, "Investment criteria for the selection of cogeneration plants-a state of the art review," Appl. Therm. Eng., vol. 26, no. 5-6, pp. 583-588, Apr. 2006.

[62] P. Mancarella and G. Chicco, "Global and local emission impact assessment of distributed cogeneration systems with partial-load models," Appl. Energy, vol. 86, no. 10, pp. 2096-2106, Oct. 2009.

[63] N. Good, E. Karangelos, A. Navarro-Espinosa, and P. Mancarella, "Optimization Under Uncertainty of Thermal Storage-Based Flexible Demand Response With Quantification of Residential Users' Discomfort," IEEE Trans. Smart Grid, vol. 6, no. 5, pp. 2333-2342, Sep. 2015.

[64] J. Xu, R. Z. Wang, and Y. Li, “A review of available technologies for seasonal thermal energy storage," Sol. Energy, vol. 103, pp. 610-638, May 2014.

[65] Z. Pan, Q. Guo, and H. Sun, "Interactions of district electricity and heating systems considering time-scale characteristics based on quasisteady multi-energy flow," Appl. Energy, vol. 167, pp. 230-243, Apr. 2016.

[66] A. Hawkes and M. Leach, "Impacts of temporal precision in optimisation modelling of micro-Combined Heat and Power," Energy, vol. 30, no. 10, pp. 1759-1779, Jul. 2005.

[67] N. Good, L. Zhang, A. Navarro-Espinosa, and P. Mancarella, "High resolution modelling of multi-energy domestic demand profiles," Appl. Energy, vol. 137, pp. 193-210, Jan. 2015.

[68] J. P. Deane, A. Chiodi, M. Gargiulo, and B. P. Ó Gallachóir, "Softlinking of a power systems model to an energy systems model," Energy, vol. 42, no. 1, pp. 303-312, Jun. 2012.

[69] M. Welsch, D. Mentis, and M. Howells, "Long-Term Energy Systems Planning:Accounting for Short-Term Variability and Flexibility," in Renewable Energy Integration, J. L. E, Ed. Academic Press, 2014, pp. 215-225.

[70] B. S. Palmintier and M. D. Webster, "Heterogeneous Unit Clustering for Efficient Operational Flexibility Modeling," IEEE Trans. Power Syst., vol. 29, no. 3, pp. 1089-1098, May 2014.

[71] L. Zhang, T. Capuder, and P. Mancarella, "Unified Unit Commitment Formulation and Fast Multi-Service LP Model for Flexibility Evaluation in Sustainable Power Systems," IEEE Trans. Sustain. Energy, vol. 7, no. 2, pp. 658-671, Apr. 2016.

[72] E. Fabrizio, V. Corrado, and M. Filippi, "A model to design and optimize multi-energy systems in buildings at the design concept stage," Renew. Energy, vol. 35, no. 3, pp. 644-655, Mar. 2010.

[73] S. Althaher, P. Mancarella, and J. Mutale, "Automated Demand Response From Home Energy Management System Under Dynamic Pricing and Power and Comfort Constraints," IEEE Trans. Smart Grid, vol. 6, no. 4, pp. 1874-1883, Jul. 2015.

[74] D. Pudjianto, P. Djapic, M. Aunedi, C. K. Gan, G. Strbac, S. Huang, and D. Infield, "Smart control for minimizing distribution network reinforcement cost due to electrification," Energy Policy, vol. 52, pp. 76-84, Jan. 2013.

[75] D. Papadaskalopoulos, G. Strbac, P. Mancarella, M. Aunedi, and V. Stanojevic, "Decentralized Participation of Flexible Demand in Electricity Markets;Part II: Application With Electric Vehicles and Heat Pump Systems," IEEE Trans. Power Syst., vol. 28, no. 4, pp. 3667-3674, Nov. 2013. 
[76] C. Weber and N. Shah, "Optimisation based design of a district energy system for an eco-town in the United Kingdom," Energy, vol. 36, no. 2, pp. 1292-1308, Feb. 2011.

[77] C. Molitor, S. Gross, J. Zeitz, and A. Monti, "MESCOS-A multienergy system cosimulator for city district energy systems," IEEE Trans. Ind. Informatics, vol. 10, no. 4, pp. 2247-2256, 2014.

[78] L. Girardin, F. Marechal, M. Dubuis, N. Calame-Darbellay, and D. Favrat, "EnerGis: A geographical information based system for the evaluation of integrated energy conversion systems in urban areas," Energy, vol. 35, no. 2, pp. 830-840, Feb. 2010.

[79] B. Morvaj, R. Evins, and J. Carmeliet, "Optimization framework for distributed energy systems with integrated electrical grid constraints," Appl. Energy, vol. 171, pp. 296-313, Jun. 2016.

[80] Z. Bao, Q. Zhou, Z. Yang, Q. Yang, L. Xu, and T. Wu, "A Multi TimeScale and Multi Energy-Type Coordinated Microgrid Scheduling Solution; Part II: Optimization Algorithm and Case Studies," IEEE Trans. Power Syst., vol. 30, no. 5, pp. 2267-2277, Sep. 2015.

[81] A. Piacentino and C. Barbaro, "A comprehensive tool for efficient design and operation of polygeneration-based energy $\mu$ grids serving a cluster of buildings. Part II: Analysis of the applicative potential," Appl. Energy, vol. 111, pp. 1222-1238, Nov. 2013.

[82] S. Bracco, F. Delfino, F. Pampararo, M. Robba, and M. Rossi, "The University of Genoa smart polygeneration microgrid test-bed facility: The overall system, the technologies and the research challenges," Renew. Sustain. Energy Rev., vol. 18, pp. 442-459, Feb. 2013.

[83] G. Kyriakarakos, D. D. Piromalis, A. I. Dounis, K. G. Arvanitis, and G. Papadakis, "Intelligent demand side energy management system for autonomous polygeneration microgrids," Appl. Energy, vol. 103, pp. 39-51, Mar. 2013.

[84] R. Niemi, J. Mikkola, and P. D. Lund, "Urban energy systems with smart multi-carrier energy networks and renewable energy generation," Renew. Energy, vol. 48, pp. 524-536, Dec. 2012.

[85] J. Keirstead and N. Shah, Eds., Urban energy systems: An integrated approach. Taylor and Francis, 2013.

[86] M. Almassalkhi and A. Towle, "Enabling City-scale Multi-energy Optimal Dispatch with Energy Hubs," in Proc. 2016 19th Power Systems Computation Conference (PSCC), in press.

[87] T. Capuder and P. Mancarella, "Assessing the Benefits of Coordinated Operation of Aggregated Distributed Multi-Energy Generation," in Proc. 2016 19th Power Systems Computation Conference (PSCC), in press.

[88] H. Lund and B. V. Mathiesen, "Energy system analysis of $100 \%$ renewable energy systems - The case of Denmark in years 2030 and 2050," Energy, vol. 34, no. 5, pp. 524-531, May 2009.

[89] J. R. Pillai, K. Heussen, and P. A. Østergaard, "Comparative analysis of hourly and dynamic power balancing models for validating future energy scenarios," Energy, vol. 36, no. 5, pp. 3233-3243, May 2011.

[90] L. Munuera, "Technology-rich economic modelling and analysis of UK residential heating systems for low carbon energy policy support," $\mathrm{PhD}$ thesis, Imperial College London, London, UK, 2014.

[91] M. Geidl and G. Andersson, "Optimal Power Flow of Multiple Energy Carriers," IEEE Trans. Power Syst., vol. 22, no. 1, pp. 145-155, Feb. 2007.

[92] M. Geidl, G. Koeppel, P. Favre-Perrod, B. Klockl, G. Andersson, and K. Frohlich, "Energy hubs for the future," IEEE Power Energy Mag., vol. 5, no. 1, pp. 24-30, Jan. 2007.

[93] T. Krause, G. Andersson, K. Fröhlich, and A. Vaccaro, "MultipleEnergy Carriers: Modeling of Production, Delivery, and Consumption," Proc. IEEE, vol. 99, no. 1, pp. 15-27, Jan. 2011.

[94] W. Leontief, Input-output economics. Oxford: Oxford University Press, 1986.

[95] K. Hemmes, J. Zachariah-Wolff, M. Geidl, and G. Andersson, "Towards multi-source multi-product energy systems," Int. J. Hydrogen Energy, vol. 32, no. 10-11, pp. 1332-1338, Jul. 2007.

[96] M. Geidl and G. Andersson, "A modeling and optimization approach for multiple energy carrier power flow," in 2005 IEEE Russia Power Tech, 2005, pp. 1-7.

[97] A. Hajimiragha, C. Canizares, M. Fowler, M. Geidl, and G. Andersson, "Optimal Energy Flow of integrated energy systems with hydrogen economy considerations," in 2007 iREP Symposium - Bulk Power System Dynamics and Control - VII. Revitalizing Operational Reliability, 2007, pp. 1-11.
[98] F. Adamek, M. Arnold, and G. Andersson, "On Decisive Storage Parameters for Minimizing Energy Supply Costs in Multicarrier Energy Systems," IEEE Trans. Sustain. Energy, vol. 5, no. 1, pp. 102-109, Jan. 2014.

[99] G. Chicco and P. Mancarella, "Matrix modelling of small-scale trigeneration systems and application to operational optimization," Energy, vol. 34, no. 3, pp. 261-273, Mar. 2009.

[100]X. Liu and P. Mancarella, "Modelling, assessment and Sankey diagrams of integrated electricity-heat-gas networks in multi-vector district energy systems," Appl. Energy, vol. 167, pp. 336-352, Apr. 2016.

[101]A. Shabanpour-Haghighi and A. R. Seifi, “An Integrated Steady-State Operation Assessment of Electrical, Natural Gas, and District Heating Networks," IEEE Trans. Power Syst., in press.

[102]M. Almassalkhi and I. Hiskens, "Optimization framework for the analysis of large-scale networks of energy hubs," in Proc. 2011 17th Power Systems Computation Conference (PSCC), 2011, pp. 1-7.

[103]C. Liu, M. Shahidehpour, and J. Wang, "Coordinated scheduling of electricity and natural gas infrastructures with a transient model for natural gas flow," Chaos An Interdiscip. J. Nonlinear Sci., vol. 21, no. 2, p. $025102,2011$.

[104]Z. Li, W. Wu, J. Wang, B. Zhang, and T. Zheng, "TransmissionConstrained Unit Commitment Considering Combined Electricity and District Heating Networks," IEEE Trans. Sustain. Energy, vol. 7, no. 2, pp. 480-492, Apr. 2016.

[105]K. R. W. Bell and A. N. D. Tleis, "Test system requirements for modelling future power systems," in IEEE PES General Meeting, 2010, pp. $1-8$.

[106]E. Trutnevyte, W. McDowall, J. Tomei, and I. Keppo, "Energy scenario choices: Insights from a retrospective review of UK energy futures," Renew. Sustain. Energy Rev., vol. 55, pp. 326-337, Mar. 2016.

[107]R. Costanza, R. D'Arge, R. de Groot, S. Farber, M. Grasso, B. Hannon, K. Limburg, S. Naeem, R. V. O’Neill, J. Paruelo, R. G. Raskin, P. Sutton, and M. van den Belt, "The value of the world's ecosystem services and natural capital," Nature, vol. 387, no. 6630, pp. 253-260, May 1997.

[108]R. S. de Groot, M. A. Wilson, and R. M. . Boumans, "A typology for the classification, description and valuation of ecosystem functions, goods and services," Ecol. Econ., vol. 41, no. 3, pp. 393-408, Jun. 2002.

[109]R. N. Allan and R. Billinton, Reliability Evaluation of Power Systems, Second. New York and London: Plenum press, 1996.

[110]T. Houghton and A. Cruden, "An investment-led approach to analysing the hydrogen energy economy in the UK," Int. J. Hydrogen Energy, vol. 34, no. 10, pp. 4454-4462, May 2009.

[111]M. Houwing and I. Bouwmans, "Agent-based Modelling of Residential Energy Generation with Micro-CHP," in Proceeding of the 2nd International Conference on Integration of Renewable and Distributed Energy Resources, 2006, pp. 1-27.

[112]C. S. E. Bale, L. Varga, and T. J. Foxon, "Energy and complexity: New ways forward," Appl. Energy, vol. 138, pp. 150-159, Jan. 2015.

[113]P. G. Taylor, P. Upham, W. McDowall, and D. Christopherson, "Energy model, boundary object and societal lens: 35 years of the MARKAL model in the UK," Energy Res. Soc. Sci., vol. 4, no. C, pp. 32-41, Dec. 2014.

[114]D. Connolly, H. Lund, B. V. Mathiesen, and M. Leahy, "A review of computer tools for analysing the integration of renewable energy into various energy systems," Appl. Energy, vol. 87, no. 4, pp. 1059-1082, Apr. 2010.

[115] G. Mendes, C. Ioakimidis, and P. Ferrão, "On the planning and analysis of Integrated Community Energy Systems: A review and survey of available tools," Renew. Sustain. Energy Rev., vol. 15, no. 9, pp. 48364854, Dec. 2011.

[116] J. Keirstead, M. Jennings, and A. Sivakumar, "A review of urban energy system models: Approaches, challenges and opportunities," Renew. Sustain. Energy Rev., vol. 16, no. 6, pp. 3847-3866, Aug. 2012.

[117]I. van Beuzekom, M. Gibescu, and J. G. Slootweg, "A review of multienergy system planning and optimization tools for sustainable urban development," in 2015 IEEE Eindhoven PowerTech, 2015, pp. 1-7.

[118]L. M. H. Hall and A. R. Buckley, "A review of energy systems models in the UK: Prevalent usage and categorisation," Appl. Energy, vol. 169, pp. 607-628, May 2016. 
[119]E. A. Martinez Cesena, T. Capuder, and P. Mancarella, "Flexible Distributed Multienergy Generation System Expansion Planning Under Uncertainty," IEEE Trans. Smart Grid, vol. 7, no. 1, pp. 348-357, Jan. 2016.

[120]P. Mancarella and G. Chicco, "Integrated energy and ancillary services provision in multi-energy systems," in 2013 IREP Symposium Bulk Power System Dynamics and Control - IX Optimization, Security and Control of the Emerging Power Grid, 2013, pp. 1-19.

[121]A. L. . Syrri and P. Mancarella, "Reliability and risk assessment of post-contingency demand response in smart distribution networks," Sustain. Energy, Grids Networks, vol. 7, pp. 1-12, Sep. 2016.

[122]F. Kienzle and G. Andersson, "A greenfield approach to the future supply of multiple energy carriers," in 2009 IEEE Power \& Energy Society General Meeting, 2009, pp. 1-8.

[123]B. Palmintier et al, "Experiences integrating transmission and distribution simulations for DERs with the Integrated Grid Modeling System (IGMS)," in Proc. 2016 19th Power Systems Computation Conference (PSCC), in press.

[124]T. J. Overbye, V. Vittal, and I. Dobson, "Engineering Resilient CyberPhysical Systems," in PSERC Publication 12-16, 2012, pp. 1-22.

[125] M. Panteli and P. Mancarella, "Influence of extreme weather and climate change on the resilience of power systems: Impacts and possible mitigation strategies," Electr. Power Syst. Res., vol. 127, pp. 259-270, Oct. 2015.
[126]Y. Wang, C. Chen, J. Wang, and R. Baldick, "Research on Resilience of Power Systems Under Natural Disasters-A Review," IEEE Trans. Power Syst., vol. 31, no. 2, pp. 1604-1613, Mar. 2016.

[127]M. Chaudry, P. Ekins, K. Ramachandran, A. Shakoor, J. Skea, G. Strbac, X. Wang, and J. Whitaker, "Building a Resilient UK Energy System," UK Energy Research Centre, April 2011.

[128]B. Wang, Y. Zhou, M. Panteli, and P. Mancarella, "Assessing the Impacts of Extreme Temperatures and Water Availability on the Resilience of the GB Power System," submitted for presentation at PowerCon 2016, Wollongong, Australia, under review.

[129]F. Kienzle, P. Ahcin, and G. Andersson, "Valuing Investments in Multi-Energy Conversion, Storage, and Demand-Side Management Systems Under Uncertainty," IEEE Trans. Sustain. Energy, vol. 2, no. 2, pp. 194-202, Apr. 2011.

[130]P. Favre-Perrod, F. Kienzle, and G. Andersson, "Modeling and design of future multi-energy generation and transmission systems," Eur. Trans. Electr. Power, vol. 20, no. 8, pp. 994-1008, Nov. 2010.

[131]E. Carpaneto, G. Chicco, P. Mancarella, and A. Russo, "Cogeneration planning under uncertainty. Part II: Decision theory-based assessment of planning alternatives," Appl. Energy, vol. 88, no. 4, pp. 1075-1083, Apr. 2011.

[132]K. R. Voorspools and W. D. D'haeseleer, "The impact of the implementation of cogeneration in a given energetic context," IEEE Trans. Energy Convers., vol. 18, no. 1, pp. 135-141, Mar. 2003. 